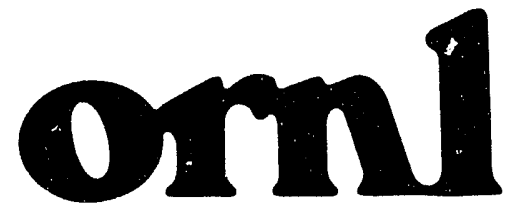

OAK RIDGE NATIONAL LABORATORY

\section{RECEIVED \\ JUL 211993 \\ OSTI}

Dynamic Impact and Pressure Analysis of the Insensitive Munitions Container PA103 with Modified Design Features

MARTIN MARUETIAd

K. D. Handy

MARTIN MARIETTA ENERGY SYSTEMS, INC. 
This report has been reproduced directly from the best available copy.

Available to DOE and DOE contractors from the Office of Scientific and Technical Information, P.O. Box 62, Oak Ridge. TN 37831; prices available from (615) 576-8401, FTS 626-8401.

Available to the public from the National Technical Information Service, U.S. Department of Commerce, 5285 Port Royal Rd. Springfield, VA 22161

This report was prepared as an account of work sponsored by an agency oi the United States Government. Neither the United States Government nor any agency thereof, nor any of their employees, makes any warranty, express or implied, or assumes any legal liability or responsibility for the accuracy. completeness, or usefulness of any information, apparatus, product, or process disclosed, or represents that its use would not infringe privately owned rights. Reterence herein to any specific commercial product, process, or service by trade name, trademark, manutacturer, or otherwise, does not necessarily coristitute or imply its endorsement, recommendation, or favering by the United States Government or any agency thereot. The views and opinions of authors expressed herein do not necessarily state or reflect those of the United States Government or any agency thereot. 


\title{
DYNAMIC IMPACT AND PRESSURE ANALYSIS OF THE INSENSITIVE MUNITIONS CONTAINER PA103 WITH MODIFIED DESIGN FEATURES
}

\author{
K. D. Handy
}

June 1993

Research sponsored by the Packaging Division, Armament Research, Development and Engineering Center (ARDEC), Picatinny Arsenal, under Interagency Agreement 1892-A078-A1 between the U.S. Department of Energy and ARDEC.

Prepared by the

OAK RIDGE NATIONAL LABORATORY

Oak Ridge, Tennessee 37831 managed by

MARTIN MARIETTA ENERGY SYSTEMS, INC.

for the

U.S. DEPARTMENT OF ENERGY

under contract DE-AC05-84OR21400 


\section{CONTENTS}

$\underline{\text { Page }}$

LIST OF FigURES $\ldots \ldots \ldots \ldots \ldots \ldots \ldots \ldots \ldots \ldots \ldots \ldots$

ABSTRACT $\ldots \ldots \ldots \ldots \ldots \ldots \ldots \ldots \ldots \ldots \ldots \ldots \ldots \ldots \ldots \ldots \ldots \ldots \ldots \ldots \ldots$

CONTAINER DESCRIPTION $\ldots \ldots \ldots \ldots \ldots \ldots \ldots \ldots \ldots \ldots \ldots \ldots \ldots$

PRESSURE ANALYSIS $\ldots \ldots \ldots \ldots \ldots \ldots \ldots \ldots \ldots \ldots \ldots \ldots \ldots$

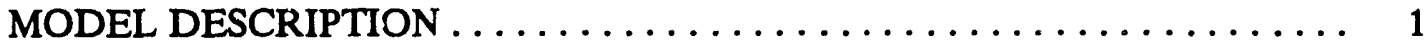

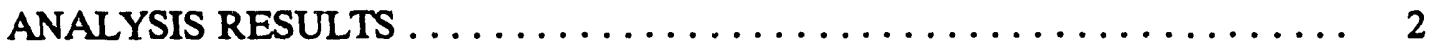

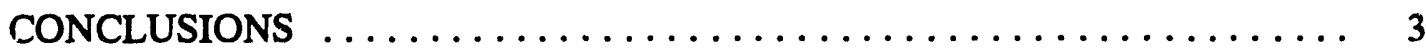

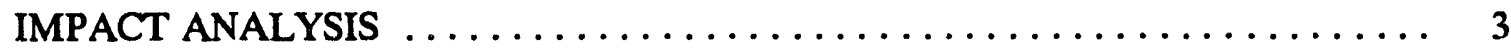

MODEL DESCRIPTION $\ldots \ldots \ldots \ldots \ldots \ldots \ldots \ldots \ldots \ldots \ldots \ldots \ldots$

SCORE PATTERNS-CRITICAL STRESS $\ldots \ldots \ldots \ldots \ldots \ldots \ldots \ldots$

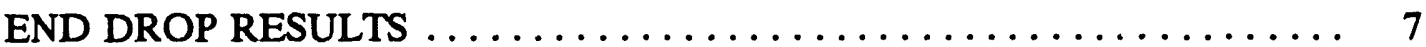

SIDE DROP RESULTS $\ldots \ldots \ldots \ldots \ldots \ldots \ldots \ldots \ldots \ldots \ldots \ldots \ldots$

CORNER DROP RESULTS $\ldots \ldots \ldots \ldots \ldots \ldots \ldots \ldots \ldots \ldots \ldots \ldots$

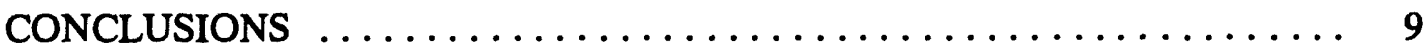

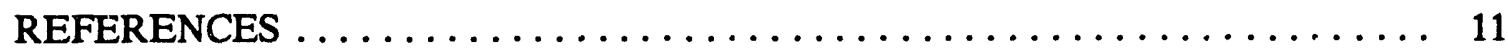




\section{LIST OF FIGURES}

No.

Title

Page

1 PATRAN/ABAQUS pressure analysis model $\ldots \ldots \ldots \ldots \ldots \ldots \ldots$

2 Deflected shape of the container assembly $\ldots \ldots \ldots \ldots \ldots \ldots \ldots \ldots$

3 Deflected shape of the container body $\ldots \ldots \ldots \ldots \ldots \ldots \ldots \ldots \ldots \ldots$

4 Contours of membrane circumferential stress $\ldots \ldots \ldots \ldots \ldots \ldots \ldots$

5 Contours of membrane longitudinal stress $\ldots \ldots \ldots \ldots \ldots \ldots \ldots \ldots$

6 Contours of membrane plus bending circumferential stress $\ldots \ldots \ldots \ldots \ldots$

7 Contours of membrane plus bending longitudinal stress $\ldots \ldots \ldots \ldots \ldots$

8 Two score patterns and the cross section of the score $\ldots \ldots \ldots \ldots \ldots$

9 Picatinny IM (PA103) 7-ft free-fall impact model . . . . . . . . . . . 20

10 Bilinear stress-strain curve assumed for $\mathrm{A} 366$ carbon steel $\ldots \ldots \ldots \ldots \ldots$

11 Bilinear stress-strain curve assumed for Formion FL $342 \ldots \ldots \ldots \ldots \ldots$

12 Bilinear stress-strain curve assumed for the charges $\ldots \ldots \ldots \ldots \ldots \ldots$

13 End drop initial model $\ldots \ldots \ldots \ldots \ldots \ldots \ldots \ldots \ldots \ldots \ldots \ldots$

14 Kinetic energy time history for the end impact $\ldots \ldots \ldots \ldots \ldots \ldots \ldots$

15 Configuration of the container assembly at various times during

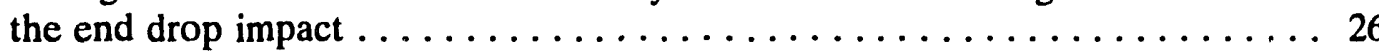

16 Configuration of the impacting fuse end of the container at various times during the end impact

17 Contours of effective stress in the body at time $=2.3987 \times 10^{-4} \mathrm{~s} \ldots \ldots \ldots 28$

18 Contours of maximum axial compressive stress in the vicinity of the lower score pattern

19 Contours of maximum axial tension stress in the vicinity

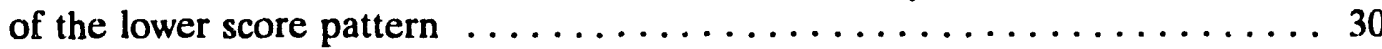

20 Contours of effective plastic strain in the body $\ldots \ldots \ldots \ldots \ldots \ldots \ldots \ldots$ 
21 Contours of effective plastic strain in the flanges and bolts $\ldots \ldots \ldots \ldots 32$

22 Kinetic energy time history for the side drop $\ldots \ldots \ldots \ldots \ldots \ldots$

23 Model configuration at various times during the side impact $\ldots \ldots \ldots \ldots . \ldots 34$

24 Contours of maximum effective stress in the body for the side drop . . . . . 35

25 Contours of maximum effective strain in the body for the side drop . . . . . 36

26 Contours of maximum effective strain in the container assembly

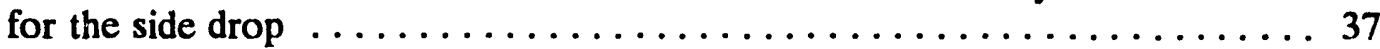

27 Effective plastic strain in the flanges due to the side drop $\ldots \ldots \ldots \ldots \ldots$

28 Maximum axial membrane stress in the body $\ldots \ldots \ldots \ldots \ldots \ldots \ldots$

29 Axial membrane stress in the body between 15,000 and 30,000 psi $\ldots \ldots \ldots 40$

30 Initial model configuration for the corner drop $\ldots \ldots \ldots \ldots \ldots \ldots \ldots$

31 Kinetic energy time history for the corner drop $\ldots \ldots \ldots \ldots \ldots \ldots \ldots$

32 Orientation of the container at $4.0 \times 10^{-3} \mathrm{~s}$ (dashed outline represents the original position) $\ldots \ldots \ldots \ldots \ldots \ldots \ldots \ldots \ldots \ldots \ldots$

33 Enlargement of the impacting corner during the initial impact $\ldots \ldots \ldots \ldots 44$

34 Orientation of the container at $1.08 \times 10^{-1} \mathrm{~s}$ (dashed outline represents the original position)

35 Orientation of the container at $1.22 \times 10^{-1} \mathrm{~s}$ (dashed outline represents the original position) $\ldots \ldots \ldots \ldots \ldots \ldots \ldots \ldots \ldots \ldots$

36 Contours of effective stress in the impacting end of the container due to initial impact $\ldots \ldots \ldots \ldots \ldots \ldots \ldots \ldots \ldots \ldots \ldots \ldots$

37 Contours of effective plastic strain in the impacting end of the container due to initial impact $\ldots \ldots \ldots \ldots \ldots \ldots \ldots \ldots$

38 Contours of axial stress in the body due to the initial impact $\ldots \ldots \ldots \ldots$

39 Maximum effective stress in the container due to the second (rim) impact ...50

40 Maximum axial membrane stress due to the second (rim) impact $\ldots \ldots \ldots . \ldots 51$ 
41 Contours of maximum effective stress due to the third impact $\ldots \ldots \ldots 52$

42 Contours of maximum axial membrane stress due to the third impact ......53 


\begin{abstract}
This report presents analytical analyses of the insensitive munitions container PA103, with modified design features for a static internal pressure of 500 psi and for a dynamic impact resulting from a 7 - $\mathrm{ft}$ free fall onto a rigid surface. The modified design features addressed by the analyses were the inclusion of a score pattern on the container cylindrical body and a plastic plate (fuse) sandwiched between metal flanges on the container end.

The objectives of both the pressure and impact analyses were to determine if the induced stresses at the score patterns in the cylindrical body of the container were sufficient to induce failure.

Analytical responses of the container to the imposed loads were obtained with finite element analysis methodology. The computer codes ABAQUS and VEC/DYNA3D were used to obtain the results.

Results of the pressure analysis indicate that failure of the container body would be expected to occur at the score pattern for a static internal pressure of 500 psi. Also, results from three impact orientations for a 7-ft drop indicate that membrane stresses in the vicinity of the score pattern are above critical crack growth stress magnitudes, especially at low $\left(-60^{\circ} \mathrm{F}\right)$ temperatures.
\end{abstract}




\section{CONTAINER DESCRIPTION}

The insensitive munitions (IM) container is basically a thin-walled steel cylinder body -36 in. long and $6.5 \mathrm{in}$. in diameter. There is a removable cover plate on one end of the cylinder and a plastic plate (fuse) sandwiched between metal flanges on the opposite end. There are three stiffening rings: one on each end and one in the middle of the cylinder. There are score patterns (described in detail later) in the body wall between the stiffener rings. Internally, there are charges with cushions on each end and a sleeve between the charges and the cylinder.

\section{PRESSURE ANALYSIS}

A pressure analysis of the container was performed to assess an accident scenario in which a unicharge ignition results in a rapid internal pressure rise in the container. $\mathrm{A}$ dynamic pressure analysis was planned; however, a time history of pressure was not available. Therefore, the analysis was performed for a static internal pressure of 500 psi.

\section{MODEL DESCRIPTION}

The analytical model for the static pressure loading was formulated with the preprocessor PATRAN ${ }^{1}$ and run with the ABAQUS ${ }^{2}$ computer code. The modeling and solutions were made on a Silicon Graphics workstation. The Picatinny drawings ${ }^{3}$ were used to obtain most of the configuration of the IM PA103 container. Details of the modified fuse end of the container were obtained by conversations with Picatinny.

A simple elastic, static internal pressure analysis was made on the body of the IM container. Figure 1 shows the PATRAN/ABAQUS model used for the pressure loading. Because of symmetry, a one-quarter model of the container was made. Boundary conditions of no deflection into or out of a plane of symmetry were made for the nodes lying on the planes of symmetry. The loading specified was a static internal pressure of 500 psi. The pressure loading was applied to the inside of the body wall and the cover plate. Pressure was not applied directly to the plastic fuse since this item was not a specific concern for the pressure analysis. Also, deflections of the plastic fuse for 500 psi would be significant with respect to deflections of the steel body and cover plate. Axial restraint was added to the container at the nodes on the body at the fuse end. Hence, the nonstiffened flexibility of the flanges/fuse would be available for radial deflections of the pressurized body. In a like manner, the cover plate at the opposite end of the body from the fuse was fictitiously thickened (to 0.5 in.) to minimize its out-of-plane deflections from the pressure. Since the cover plate was not specifically an item of concern for the pressure analysis and since the rim stiffening ring attaches to the body close to the cover plate attachment, the influence of the thickened cover plate on the deflections of the body is minimal. The translations of adjacent nodes on the interfaces between the flanges-to-fuse, flange-tobody, and body-to-stiffener rings were coupled. Components internal to the cylindrical body (charges, cushions, and sleeve) were not modeled.

Elastic material properties were input to the ABAQUS model. The components of the container are all taken to be $\mathrm{A} 366$ carbon steel $^{3}$ except the fuse, which is a plastic, 
Formion FL342. The material properties were assumed to be for room temperature conditions.

The American Society for Testing and Materials (ASTM) requirements for A366 are for a commercial quality, cold-rolled carbon steel sheet. The strength requirements are as follows: "The material shall be capable of being bent, at room temperature, in any direction through 180 degrees flat on itself without cracking on the outside of the bent portion. ${ }^{.4}$ Strength properties for mild steel were assumed for the A366 material. A stress-strain curve for mild steel was obtained from Engineering Design. ${ }^{5}$ From the stressstrain curve, the following elastic material properties were assumed for the A366 material: a modulus of elasticity of $30 \times 10^{6} \mathrm{psi}$ and a Poisson's ratio of 0.3 .

A data sheet was obtained from Picatinny for the material properties of the Formion FL342. From the data, a tensile breaking strength of 2603 psi at $200 \%$ strain was obtained. An elastic curve to the tensile breaking strength could be used; however, a slightly curved stress-strain curve was assumed and a bilinear curve was fit to the assumed stress-strain curve (see the impact analysis for details). The elastic material properties for the Formion are assumed to be an elastic modulus of $4000 \mathrm{psi}$ and a Poisson's ratio of 0.3 .

A simple verification run was made on ABAQUS with a model that contained only a bare cylinder body and an end cover plate. The boundary conditions on the simple model were the same as those used on the complete model. The results compare favorably with the theoretical results for a static internal pressure. For the hoop stress, $p r / t=34,403 \mathrm{psi}$ (pressure is $500 \mathrm{psi}$, the radius is the mean radius $3.2889 \mathrm{in}$. , and the wall thickness is 0.0478 in.). The longitudinal stress is $p r / 2 t=17,201$ psi. Results from the simple verification model show that the membrane circumferential stress is nominally $34,114 \mathrm{psi}$ (99.16\% of theoretical) and that the membrane longitudinal stress is nominally $17,056 \mathrm{psi}$ ( $99.16 \%$ of theoretical).

\section{ANALYSIS RESULTS}

Figures 2 and 3 show deflected shapes of the complete pressurized container assembly. Figure 2 shows the complete model assembly deflected shape superimposed on the undeflected shape. Figure 3 shows only the deflected shape of the container body superimposed on the undeflected shape. A slight ovalization of the body between the stiffeners can be seen in Fig. 2. This is probably caused by the nonconcentric geometry of the stiffener rings and rim. Contours of membrane stress are given in Figs. 4 and 5. Figure 4 shows the circumferential membrane stress with a maximum contour range of 32,700 to 35,700 psi, and Fig. 5 shows the membrane longitudinal stress with a maximum contour range of 15,700 to 17,600 psi. Contours of membrane plus bending stress are given in Figs. 6 and 7. Figure 6 shows the circumferential membrane plus bending stress with a maximum contour range of 33,900 to $36,700 \mathrm{psi}$. The circumferential membrane plus bending contours echo the ovalization of the body noted in Fig. 2. Figure 7 shows the longitudinal membrane plus bending stress with a maximum contour range of 17,700 to 19,100 psi. As can be seen in Figs. 4 to 7, the maximum membrane and membrane plus bending stress ranges exist between the stiffeners (rim and rings), which is where the score patterns are located.

The score patterns are three-quarters of the thickness, as shown in cross section in Fig. 8. According to Picatinny, the score patterns are cut with a circular cutting wheel; therefore, the radius of curvature at the base of the score pattern is very small and would 
be the radius on the side of a tooth on the cutting wheel. Hence, a quantitative radius at the base of the score pattern is not known, but it is qualitatively known to be very small. By assuming a radius, a stress concentration factor as given in Stress Concentration Factors $^{6}$ can be found. The stress concentration factors given in Ref. 6 depend upon the ratios $D / d$ and $r / d$ (Fig. 8). $D / d$ for the score patterns is $4(d=0.25 D)$. The greatest $D / d$ ratio given by Ref. 6 curves is 2 . Therefore, an actual stress concentration factor would be greater than one obtained from the $D / d=2$ curve in Ref. 6 . Assuming a radius of 0.001 in. gives an $r / d$ of 0.0833 and results in stress concentrations (for $D / d=2$ ) of 2.7 for tension and 2.8 for bending loadings. Smaller radii than 0.001 in. will give increasing values of stress concentration. Larger radii will give decreasing values of stress concentration. The stress concentration factors obtained in Ref. 6 were applied to the nominal stress in the reduced region of the notch ( $d$ in Fig. 8).

Using simple strength-of-material principles, the nominal membrane stress in the reduced region of the notch will be approximately four times the nominal stress determined in the ABAQUS model (the score pattern thickness is reduced by 4). Therefore, the nominal circumferential membrane stress at the reduced cross section of the score mark is nominally between $130,800(32,700 \mathrm{psi} \times 4)$ and $142,800 \mathrm{psi}$. The nominal longitudinal membrane stress at the reduced cross section is between 62,800 and 70,400 psi. The through-wall bending stress at the nominal score pattern thickness would be increased because of the eccentricity of the membrane loading between the nominal body wall and the nominal score pattern wall. This increased bending effect is not calculated here because the relative magnitudes of the membrane stresses alone are well above a yield stress and membrane failure is a primary failure mode.

Application of the stress concentration factors gives very high states of stress at the corners of the score patterns for a pressure loading of 500 psi. The intensified circumferential stress at the possible locations of the score patterns is between 353,160 and $385,560 \mathrm{psi}$. The intensified longitudinal membrane stress is between 169,560 and 190,080 psi.

\section{CONCLUSIONS}

The intensified membrane stress levels determined in the pressure analysis show that for a uniform, static pressure loading, the corners of the score patterns develop the highest membrane stress, followed by the nominal membrane stress in the reduced region of the score patterns and then the nominal stress in the full thickness wall. Even without quantitative data on the material properties of the A366 material, the above membrane stress magnitudes clearly indicate that the region around the score pattern would be well above membrane yield for a pressure of 500 psi. Given the primary loading condition of pressure, the container body would be expected to fail initially at the score patterns in a static internal pressure loading of 500 psi.

\section{IMPACT ANALYSIS}

An impact analysis of the IM container was performed to assess the performance of the modified areas of the container. A primary objective was to determine if failure of the container at the score patterns was a likely scenario. 


\section{MODEL DESCRIPTION}

Three orientations of the container in 7-ft free fall impacts were made: end, side, and corner. In the end drop, the axis of the container was vertical with the fuse end of the container striking a rigid surface. The side drop was onto the side of the container with the axis of the container initially parallel to the rigid surface. For the corner drop, the axis of the container was initially at $45^{\circ}$ to the rigid surface and the fuse end striking the surface. The corner drop simulation was allowed to continue until the secondary impacts due to the translation and rotation of the container reached a negligible magnitude.

The analytical simulation of the impacts onto a rigid surface was modeled with the preprocessor INGRID. ${ }^{7}$ VEC/DYNA, ${ }^{8}$ a nonlinear, explicit finite element code, was used for the solution. TAURUS ${ }^{9}$ was used as the postprocessor. All work was done on Silicon Graphics workstations.

The model used for the impact drops is shown in an exploded view in Fig. 9. Beciause of symmetry, a one-half model was used for all the drops. The cover plate, body, rim, and rings were modeled with plate elements, while the charges, flanges, fuse, and bolts were modeled with 8-node brick elements. The cushions and sleeve shown in Dwg. 12937952 (ref. 3) were not specifically modeled.

Slidelines were used to join various parts of the model. These slidelines allow separation and sliding but not penetration among other parts of the model. Tied slidelines (translations for adjacent nodes are coupled) were used to attach the rim and rings to the body. Tied slidelines were also used to attach the flange to the body and the bolting to the flanges. Slidelines with friction were used on the interfaces of the charges to the body, cover plate, and fuse and between the fuse and the flanges. The nodes of the bolt elements were merged with the adjacent nodes on the fuse. Therefore, the fuse could slide between the flanges and separate from the flanges, but the fuse was attached to the bolting. The and flange could separate from the fuse except at the bolts, where it is restrained. This model presents a fairly realistic bolted joint except that preload from the bolts was not included.

Quantitative material data for the various materials in the container were minimal. Many assumptions had to be made to model the materials. A bilinear model was assumed for all the materials.

The body, rim, rings, and flanges are modeled as A366 material. ${ }^{3}$ As mentioned in the static pressure analysis, quantitative data for the A366 material properties are assumed. The curve ${ }^{5}$ for mild steel materials is approximated in the Fig. 10 bilinear stress-strain curve. The modulus of elasticity was assumed to be $30 \times 10^{6} \mathrm{psi}$, and Poisson's ratio was assumed to be 0.30 . A yield stress of 30,000 psi is assumed, and a plastic modulus of 125,000 psi was determined from the assumed bilinear stress-strain curve. These material properties are assumed to be at room temperature. A density of $490 \mathrm{lb} / \mathrm{ft}^{3}$ was also assumed.

The fuse material is Formion FL342, and a tensile breaking strength of 2600 psi at $200 \%$ strain was given in the data sheet mentioned in the pressure analysis. From these data, a bilinear curve as shown in Fig. 11 was assumed. From the assumed bilinear curve, the modulus of elasticity was calculated to be 4000 psi with a yield of 1000 psi and a calculated plastic modulus of 916 psi. Density of the Formion was given as $64.9 \mathrm{lb} / \mathrm{ft}^{3}$ in the data sheet.

According to conversations with Picatinny personnel, the internal charges are relatively hard and will not dent with thumb pressure. Lacking other data for the charges, 
a model previously derived for plywood loaded perpendicular to the laminations was used for the charges. This model would represent a material that is relatively hard with respect to human handling but is relatively soft compared to steel. The bilinear curve for the model is shown in Fig. 12. The charges weigh $28 \mathrm{lb}^{10}$ The density for the charges was adjusted in the model such that the total weight of the charges is $28 \mathrm{lb}$.

The container body was modeled as a uniform thin wall surface. Fracture mechanics concepts were applied in an effort to exirapolate the response of the modeled container to that of a container with the score patterns. This approach allows only one model to be run for each drop configuration. The maximum stresses within the possible score pattern locations may then be user as though the score patterns existed at the location of maximum stress.

\section{SCORE PATTERNS-CRITCAL STRESS}

Reference 11 gives many configurations for cracks/loadings and the corresponding stress intensity factor. The one chosen as best fitting the score patterns is that of a circumferential slot in a cylinder loaded with a static axial tension (Ref. 11, case 33.3). The equation given in Ref. 11 for the stress intensity is

$$
K_{I}=\sigma \sqrt{R}(\sqrt{2} / \varepsilon)^{(1 / 2)} F(\theta),
$$

where,

$$
\begin{aligned}
& F(\theta)=\theta+\frac{1-\theta \cot \theta}{2 \cot \theta+\sqrt{2} \cot \left(\frac{\pi-\theta}{\sqrt{2}}\right)}, \\
& \varepsilon^{2}=\frac{(t / R)}{\sqrt{12\left(1-v^{2}\right)}}, \\
& R=\text { mean radius of cylinder, } \\
& t=\text { cylinder wall thickness, } \\
& 2 \theta=\text { arc length of the existing crack (score pattern), } \\
& K_{I}=\text { stress intensity factor. }
\end{aligned}
$$

The circumferential score pattern is 7 in. in length. Its arc length is then

$$
\frac{2 \theta}{360^{\circ}}=\frac{7 \text { in. }}{20.86} \text { in. }-\theta=60^{\circ} \text {. }
$$


Substituted,

$$
F(\theta)=1.3556,
$$

and fo: $t=0.0478$ in. and $R=3.32$ in.,

$$
\varepsilon=0.066 \text {. }
$$

Substituting into the stress intensity equation,

$$
K_{I}=\sigma(11.4337) \sqrt{\text { in. }} .
$$

From Elementary Engineering Fracture Mechanics, ${ }^{12}$ page 183, the critical stress intensity factor $\left(K_{I_{c}}\right)$ for low-strength carbon steel at room temperature is greater than $200 \mathrm{ksi}$ $\left(\right.$ in. $\left.{ }^{1 / 2}\right)$. Setting the stress intensity equal to the critical stress intensity results in

$$
200 \mathrm{ksi} \sqrt{\text { in. }}=\sigma_{c}(11.4337) \sqrt{\text { in. }} .
$$

Solving for the critical stress,

$$
\sigma_{c}=17.5 \mathrm{ksi},
$$

which is the minimum stress level at which cracking will grow for the loading case of static axial tension (membrane) on the cylinder at room temperature.

In Fracture Mechanics Design Handbook, ${ }^{13}$ page 213, a case was found for a harmonic stress wave impinging normally to a line crack (for the case at hand, the initial crack is the score mark). The data given in Ref. 13 are those of a multiplication factor applied to the static loading case based on the impinging stress wave length and the length of the score mark. As the container strikes the rigid surface, a compression stress wave initiates and travels to the opposite end of the container. As the free surfaces are reached, the compression wave is reflected as a tension wave. Taking the wave length as twice the length of the container, a multiplication factor of 1.18 for the static case is found. Applying this factor to the above static axial loading case gives a critical stress of

$$
\sigma_{c}=\frac{17.5 \mathrm{ksi}}{1.18}=14.8 \mathrm{ksi}
$$

for cracking to be initiated.

Changes in the material properties will occur as the temperature ranges from -60 to $+160^{\circ} \mathrm{F}$. The assumed material properties used in this calculaiion are also assumed to be at room temperature. As the temperature increases to $+160^{\circ}$, no appreciable change would be expected in the assumed A366 material parameters or model results based on known property curves for similar materials. As the temperature decreases to $-60^{\circ}$, the assumed carbon steel yield and ultimate strength may classically increase. The result would be that the deformations in the container body may not be as severe as predicted.

However, as the strength of steel increases with decrease in temperature, ductility 
decreases. Changes to the material properties for Formion FL342 and the internal charges are not known.

Many factors can influence the critical fracture toughness $\left(K_{I c}\right)$ even if a specific material fracture toughness is known. Three of the factors are specimen residual stress, temperature, and thickness. ${ }^{12}$ If compressive residual stresses remain after the formation of the score pattern on the body of the container, then crack growth could be inhibited. However, if there is a tensile residual stress field remaining, then crack growth could be e.hanced. Qualitatively, values of $K_{l c}$ decrease with lower temperatures and increase with higher temperatures. Specimen thickness affects the state of stress at the tip of a srack. The reported $K_{I c}$ values for materials [200 ksi (in. ${ }^{1 / 2}$ ) in this analysis] are found for the case of plane strain for which a relatively thick specimen is needed. A thin specimen (as with the container body) develops plane stress at the crack tip. For plane stress, a higher value of $K_{l c}$ can be applied before the crack will grow. However, there is a thickness beneath which there is uncertainty about the effect on critical fracture toughness. Some researchers have shown that beneath this thickness the $K_{I c}$ actually decreases.

\section{END DROP RESULTS}

The initial configuration of the end drop is shown in Fig. 13. The relatively rigid surface is not shown in the figure but analytically exists just below the outer flange on the end of the container. The kinetic energy time history for the impact is shown in Fig. 14. The minimum energy for the stiffer steel container is reached near $4.5 \times 10^{-4} \mathrm{~s}$; however, the minimum kinetic energy for the charge and container system is not reached until $2.75 \times 10^{-3} \mathrm{~s}$. The configuration of the model assembly at various times during the impact is shown in Fig. 15. An enlargement of the impacting fuse end of the container is shown in Fig. 16 at various times during the end impact.

Figure 17 shows the maximum effective membrane stress contours in the metal parts of the container at a time of about $2.4 \times 10^{-4} \mathrm{~s}$. The maximum $z$-stress compression wave (axial for the container) is shown in Fig. 18, with the maximum compression $(-31,600$ to $-30,000 \mathrm{psi}$ ) being absent in color in the figure. The color red in the figure indicates stresses greater than $-29,000 \mathrm{psi}$. The maximum compression wave occurs in the vicinity of the lower score pattern at about a time of $2.4 \times 10^{-4} \mathrm{~s}$. The subsequent tension wave in the body diminishes in magnitude and is shown in Fig. 19 to be $\sim 15,000$ psi in the vicinity of the lower score pattern. Figure 20 shows the maximum effective plastic strain in the body at about time $=4.5 \times 10^{-4} \mathrm{~s}$. The figure shows that the lower part of the body will exceed the assumed yield and reach an effective membrane plastic strain between 0.0 and $2.179 \times 10^{-3} \mathrm{in}$./in. Figure 21 shows some effective plastic strain evident in the flange that welds to the body. This effective plastic strain may be indicative of the specific way the bolting was modeled; however, slight plastic strain occurring in the flange should not be disregarded.

From Fig. 19 the maximum axial membrane tensile stress cause by a 7 - $\mathrm{ft}$ end drop was found to be about $15,000 \mathrm{psi}$ in the vicinity of the lower score pattern. This is approximately equal to the critical stress value (14,800 psi); hence, crack growth is possible at one of the ends of the circumferential score marks.

The actual score pattern geometry could significantly reflect the stress wave since the score pattern removes three-quarters of the wall thickness. A stress wave propagating at $90^{\circ}$ to the circumferential score mark could, in essence, see a reflective free surface at the 
deeply cut score mark. If this occurs, then a tensile stress level approximately equal in magnitude to the compressive stress wave (because the travel distance is small in relation to the total length of the body) could be expected. This would give a tensile stress wave of nearly 30,000 psi at the score pattern. A stress of this magnitude could result in crack growth at one of the ends of the circumferential score marks.

\section{SIDE DROP RESULTS}

The kinetic energy time history for the side drop is shown in Fig. 22. The model configuration at various times during the impact is shown in Fig. 23. Contours of maximum effective membrane stress in the body are given in Fig. 24. Contours of maximum effective strain in the body are shown in Fig. 25, and an assembly view from the outside of the container is shown in Fig. 26. Some minor plastic deformation in the flanges would be expected based on the contour plot of effective plastic stain given in Fig. 27.

Figure 28 shows the maximum axial membrane stress in the container body. As would be expected for a side drop, tension exists between the rings and rim at the impacting side of the body with compression on the opposite side of the impact in the body. Because membrane tensile stress levels above 14,800 psi are of interest, a contour range between 15,000 and 30,000 psi is shown in Fig. 29. The high stress region contoured in the side of the body and near the middle of Fig. 29 is due to ovalization of the body and the interaction of the ring stiffener. Based on Figs. 25, 28, and 29, it can be seen that axial membrane stress well in excess of the critical stress of 14,800 psi would be expected in the region of the body nearest the impact. Therefore, crack growth initiating from the score pattern could be expected.

\section{CORNER DROP RESULTS}

The initial orientation for the corner drop is shown in Fig. 30. The initial impact was with the axis of the container at $45^{\circ}$ to the impacting surface and the fuse end just at the rigid surface. The analysis was allowed to continue until the secondary impacts due to the rotation and translation of the container were minimal. Gravity was included in this run since the configuration of the container after the initial corner impact dealt with subsequent fall distances and rotations of considerable duration. Figure 31 shows the complete time history for the kinetic energy of the container system. The initial impact minimum kinetic energy occurs at about $4.0 \times 10^{-3} \mathrm{~s}$. Figure 32 shows the orientation of the container at $4.0 \times 10^{-3} \mathrm{~s}$. The dashed lines in Fig. 32 represent the initial configuration of the container. An enlargement of the impacting end is shown in Fig. 33. The container then rotates as it falls and strikes the rigid surface at the rim end for the second impact, as shown in Fig. 34. Minimum kinetic energy for the second impact occurs at approximately $1.08 \times 10^{-1} \mathrm{~s}$. A third major impact then occurs at approximately $1.22 \times$ $10^{-1} \mathrm{~s}$, with the orientation of the container shown in Fig. 35. After the third impact, the container continues to rock and descend with minimal energy and impact as it is coming to rest on the rigid surface.

Contours of effective stress at time $4 \times 10^{-3} \mathrm{~s}$ in the impacting corner of the container are shown in Fig. 36. Effective plastic strain in the metal parts of the impacting end are shown in Fig. 37. As in the end drop model, this plastic strain may be due to the 
specific modeling configuration; however, as seen in Fig. 37, some plastic deformations in the flanges near the impact could be expected. As seen in Fig. 38, the maximum axial membrane stress for the initial impact occurs at $4.2 \times 10^{-3} \mathrm{~s}$ and is localized in an area that could be a possible score pattern location near the impacting end. A review of the time states shows that the 14,310-psi axial membrane stress occurs briefly and does not travel along the body.

Contours of maximum effective stress due to the second (rim) impact occur at about $1.08 \times 10^{-1} \mathrm{~s}$ and are shown in Fig. 39. The magnitude of the maximum axial membrane stress due to the second impact is over 30,000 psi; however, it appears to be localized at the stiffener rings and the rim. The axial membrane stress in the body between 15,000 and 25,000 psi is contoured in Fig. 40. The regions above 15,000 psi appear to be removed from the score pattern locations in Fig. 40.

Contours of maximum effective membrane stress due tc the third impact occur at about $1.22 \times 10^{-1} \mathrm{~s}$ and are shown in Fig. 41. The magnitude of the maximum axial membrane stress is about 20,480 psi and occurs at $1.224 \times 10^{-1} \mathrm{~s}$, as shown in Fig. 42. Even though less in magnitude than the second impact, the location of the axial membrane stress in excess of 15,000 psi could be in the location of a score pattern.

Reviewing the complete corner drop results in summary, the general axial membrane stress in the vicinity of a score pattern appears to be just at the critical stress magnitude. Axial membrane stress magnitudes well in excess of the critical stress (second impact) appear to remain localized to the stiffener rings and the rim and do not appear to be a stress wave in the body. These axial stresses in the second impact are probably due to the interaction of the body, which is trying to ovalize, and the stiffener rings. However, because of the stress in the body near the critical stress, some slight cracks at the score. pattern may occur.

\section{CONCLUSIONS}

The three impact orientations for the 7-ft drop indicate that axial membrane stress in the body wall will be at or above the calculated critical stress magnitude. The highest axial membrane stress that would occur in the vicinity of a score pattern was found in the side drop. If a score pattern existed in the body nearest the impact, then crack growth could be initiated from the score pattern. As discussed in the end drop, if stress waves are reflected from the lower score pattern, then crack growth could be seen at the lower score pattern. If a significant part of the initial compressive wave is not reflected in the end drop, then the end drop and the corner drop predict axial membrane tension stresses just at the critical stress level. Some crack growth could possibly be experienced in the end drop and on the lower side of the body in the corner drop. Greater crack growth would be expected at the lower $\left(-60^{\circ} \mathrm{F}\right)$ temperature because of the increased brittleness classically expected in the A366 material. The response of the container at the greater $\left(+150^{\circ} \mathrm{F}\right)$ temperature extreme would not be expected to change significantly from the predicted levels. 


\section{REFERENCES}

1. PATRAN, Release 2.5-3, PDA Engineering.

2. ABAQUS, Version 5.2, Hibbitt, Karlsson and Sorensen, Inc., 1992.

3. Picatinny Drawings:

9331679 - Body

9331680 - Rim

9331681 - Ring

9331684 - Body Weldment

9349398 - Container, Ammo, Metal

12937952 - Packing and Marking

A112092 - Top Flange Inside Rim Restricting Sleeve

4. Standard Specification for Steel, Sheet, Carbon, Cold-Rolled, Commercial Quality, American Society for Testing and Materials, A366/A366M-85, Vol. 01.03, 1985.

5. Joseph H. Faupel, Engineering Design, Wiley, 1964.

6. R. E. Peterson, Stress Concentration Factors, Wiley, 1974.

7. S. W. Stillman and J. O. Hallquist, INGRID: A Three-Dimensional Mesh Generator for Modeling Nonlinear Systems, UCID-20506, Lawrence Livermore National Laboratory, July 1985.

8. J. O. Hallquist and D. W. Stillman, VEC/DYNA3D User's Manual Nonlinear Dynamic Analysis of Structures in Three Dimensions), LSTC Report 1018, Livermore Software Technology, June 1990.

9. B. E. Brown and J. O. Hallquist, TAURUS: An Interactive Post-Processor for the Analysis Codes NIKE3D, DYNA3D, TACO3D AND GEMINI, UCID-19392, Rev. 1, Lawrence Livermore National Laboratory, May 1984.

10. Telex received Sept. 18, 1992, from Picatinny concerning questions raised in a Sept. 9, 1992, meeting.

11. Hiroshi Tada, Paul C. Paris, and George R. Irwin, The Stress Analysis of Cracks Handbook, Paris Productions, Inc., 2nd ed., 1985.

12. David Broek, Elementary Engineering Fracture Mechanics, Martinus Nijhoff Publishers, 3rd rev. ed., 1984.

13. Fracture Mechanics Design Handbook, Technical Report-77-8, U.S. Army Missile Research and Development Command, Redstone Arsenal, Alabama, Aug. 17, 1977. 


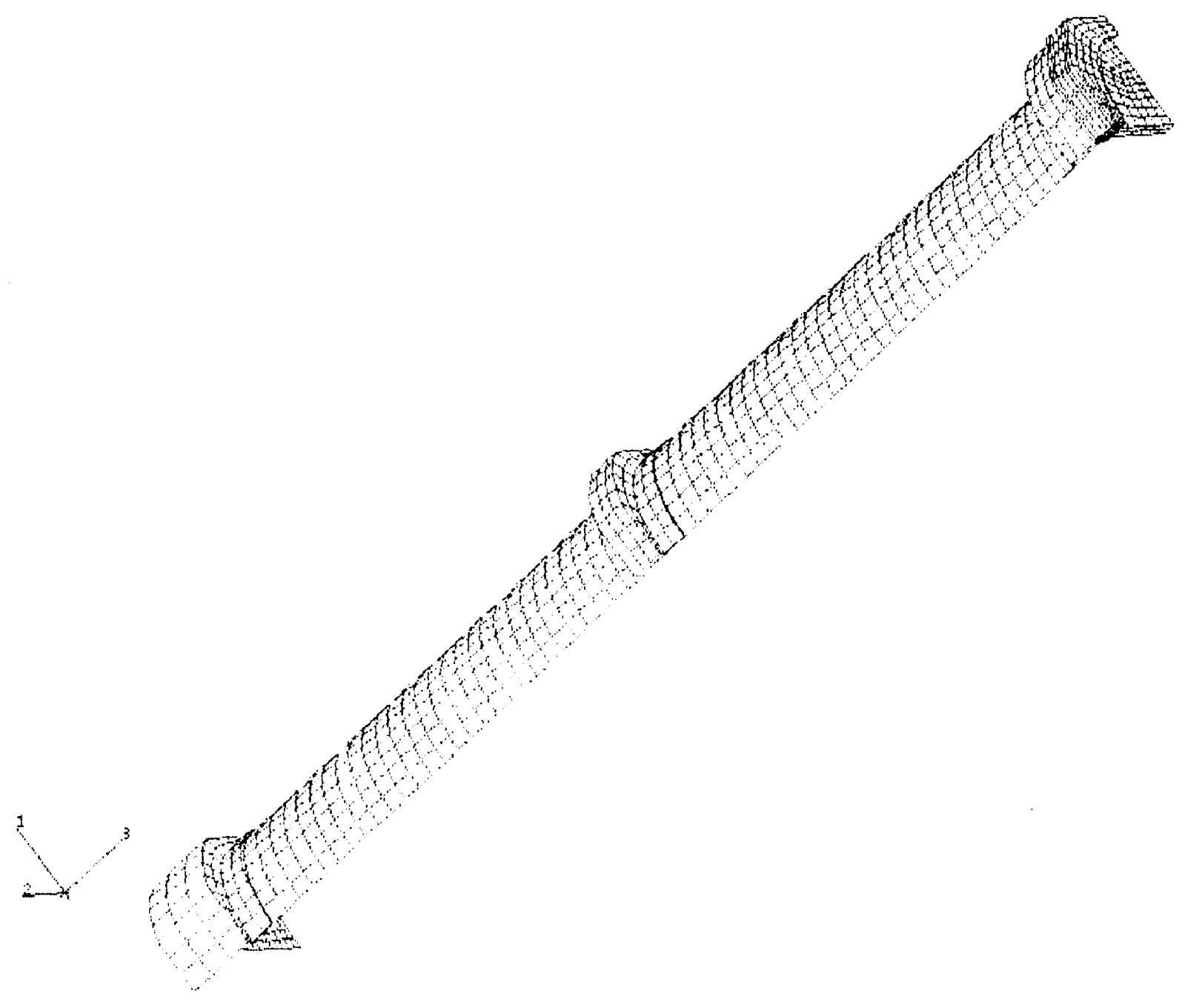

Fig. 1. PATRAN/ABAQUS pressure analysis model. 


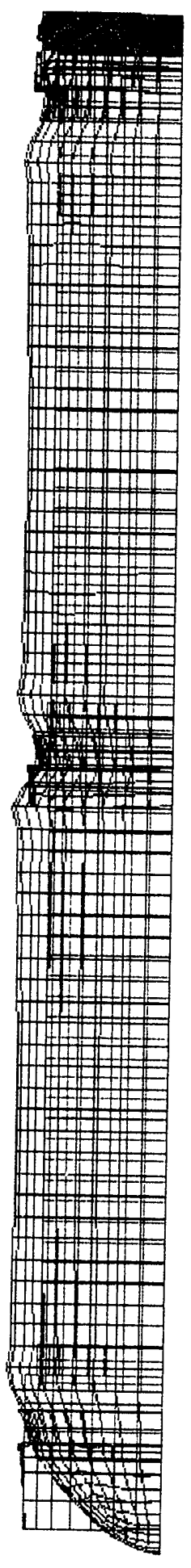

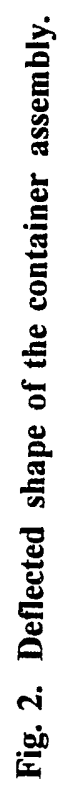




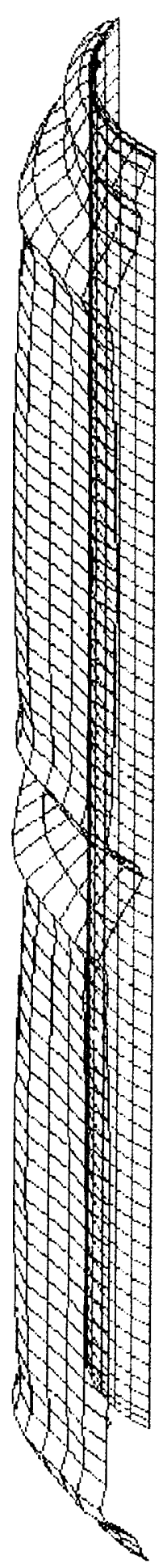

हैं

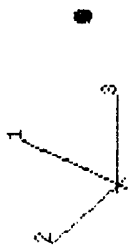




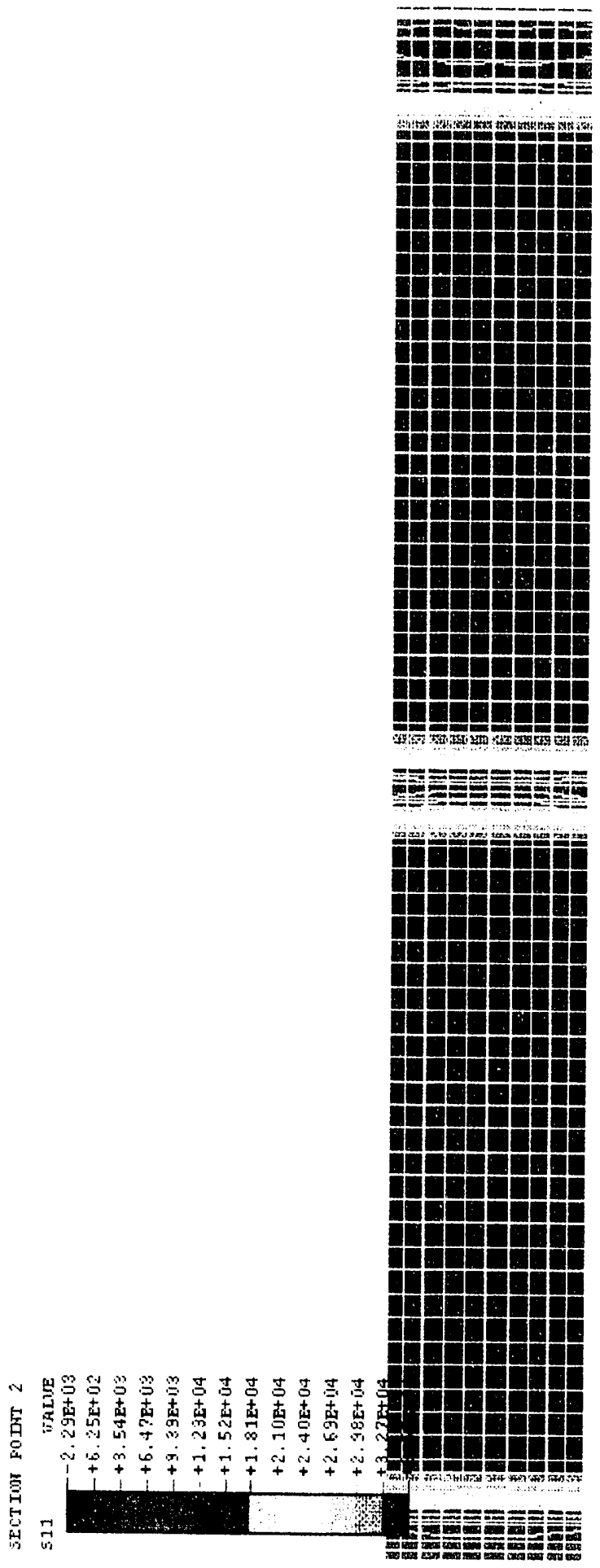

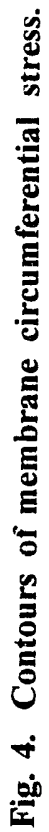




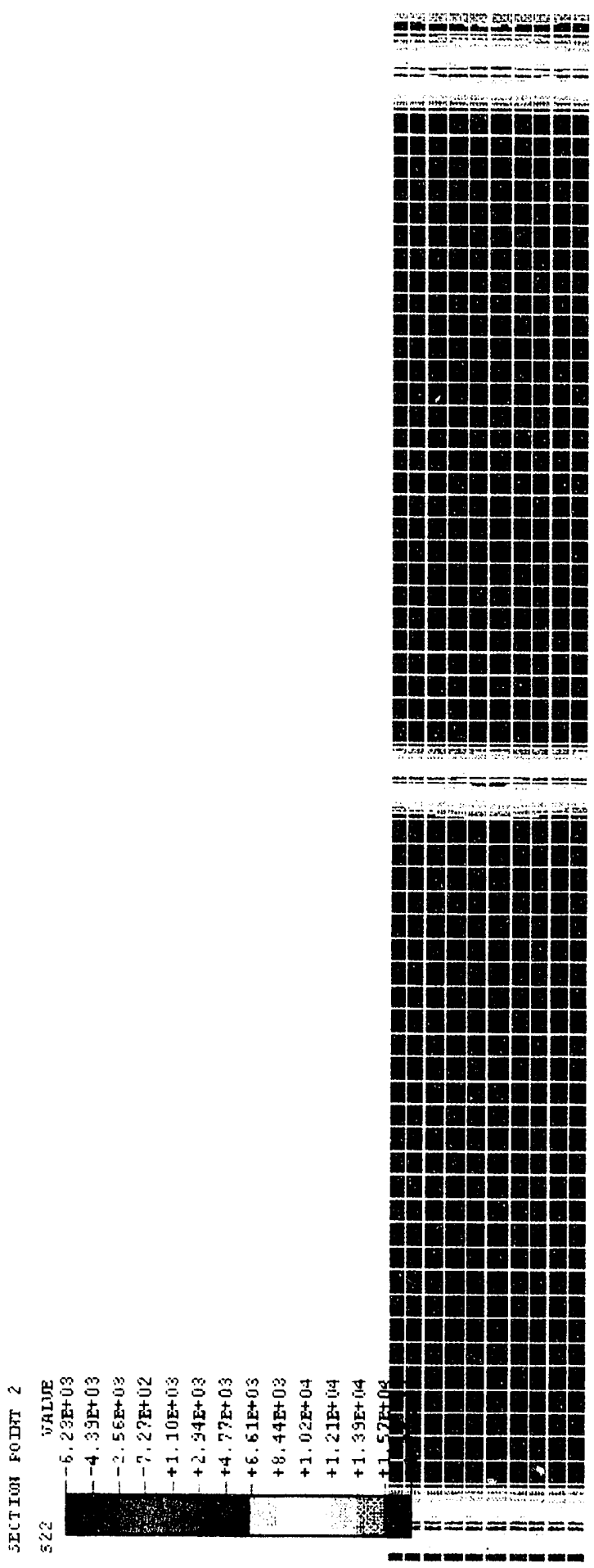




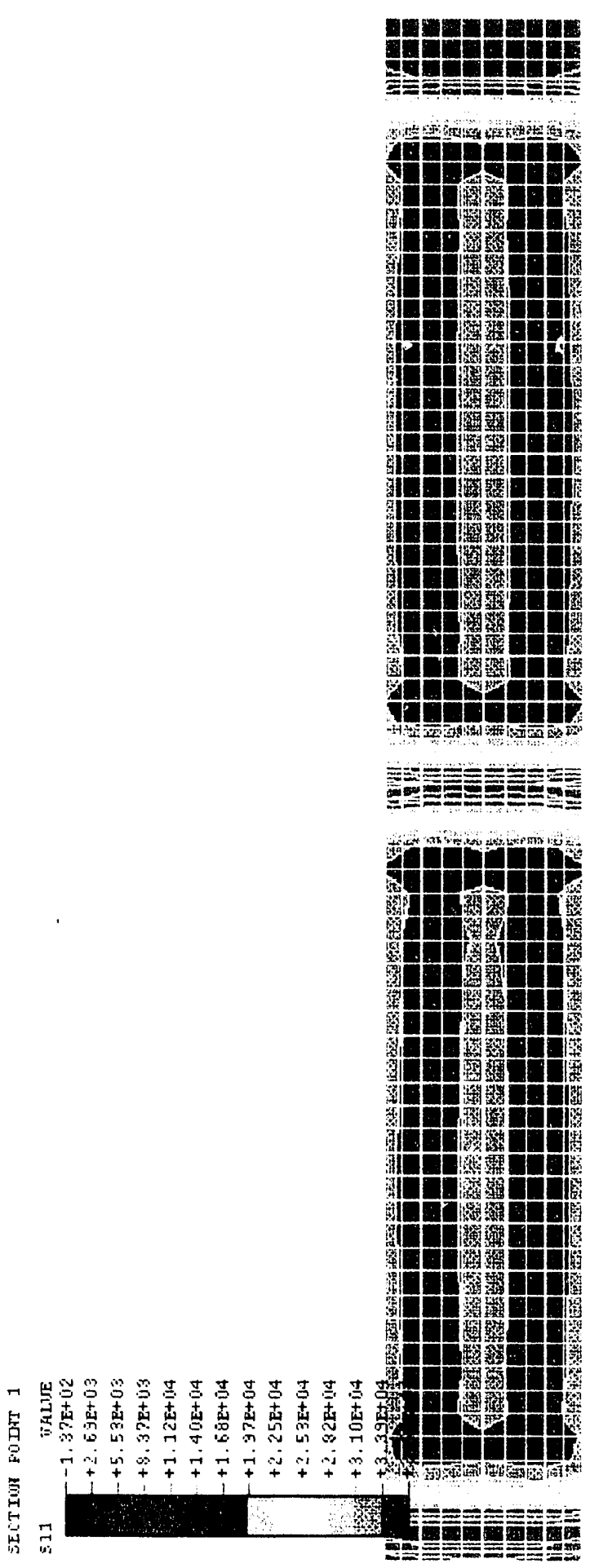




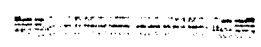

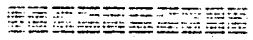

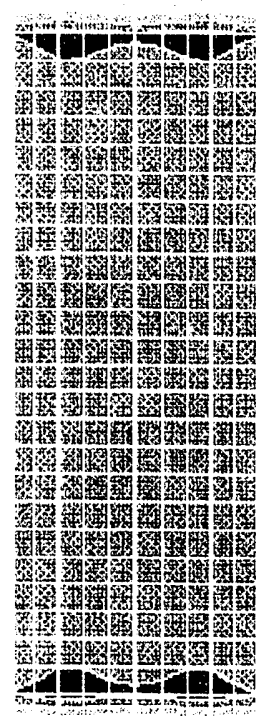

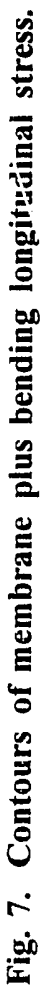

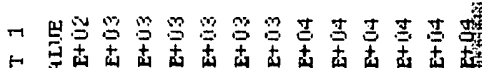

$=$

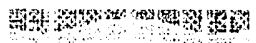
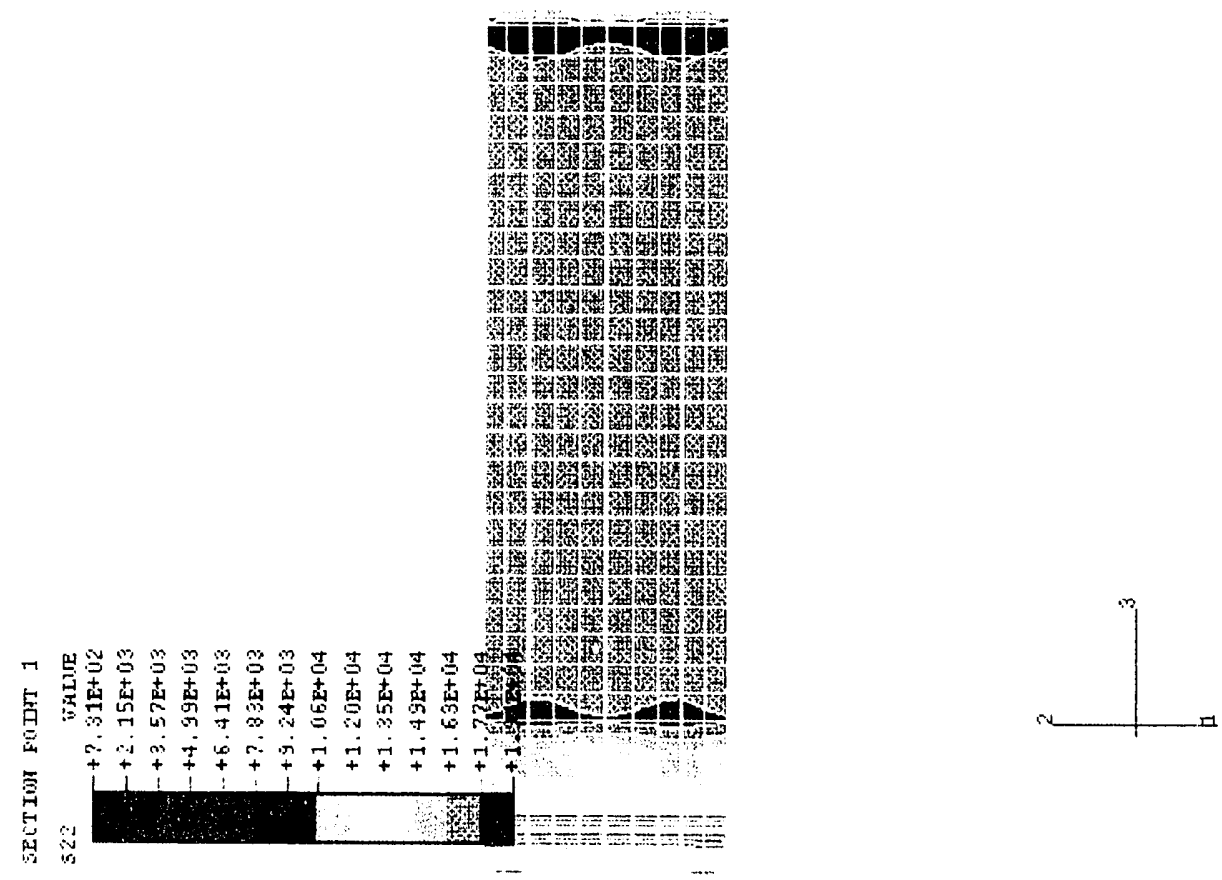
" $"$ " SCORE PATTERN

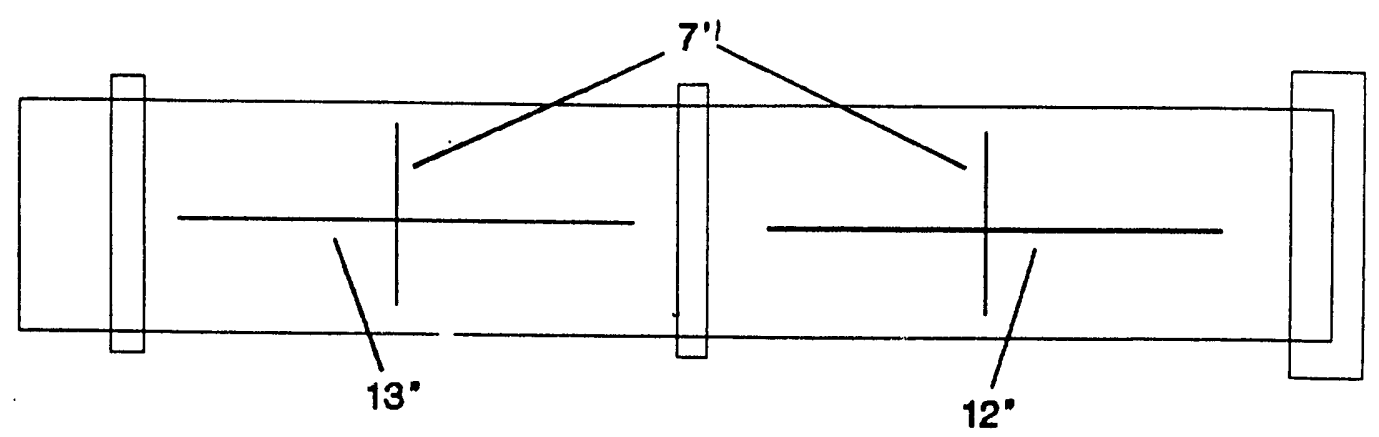

"H" SCORE PATTERN
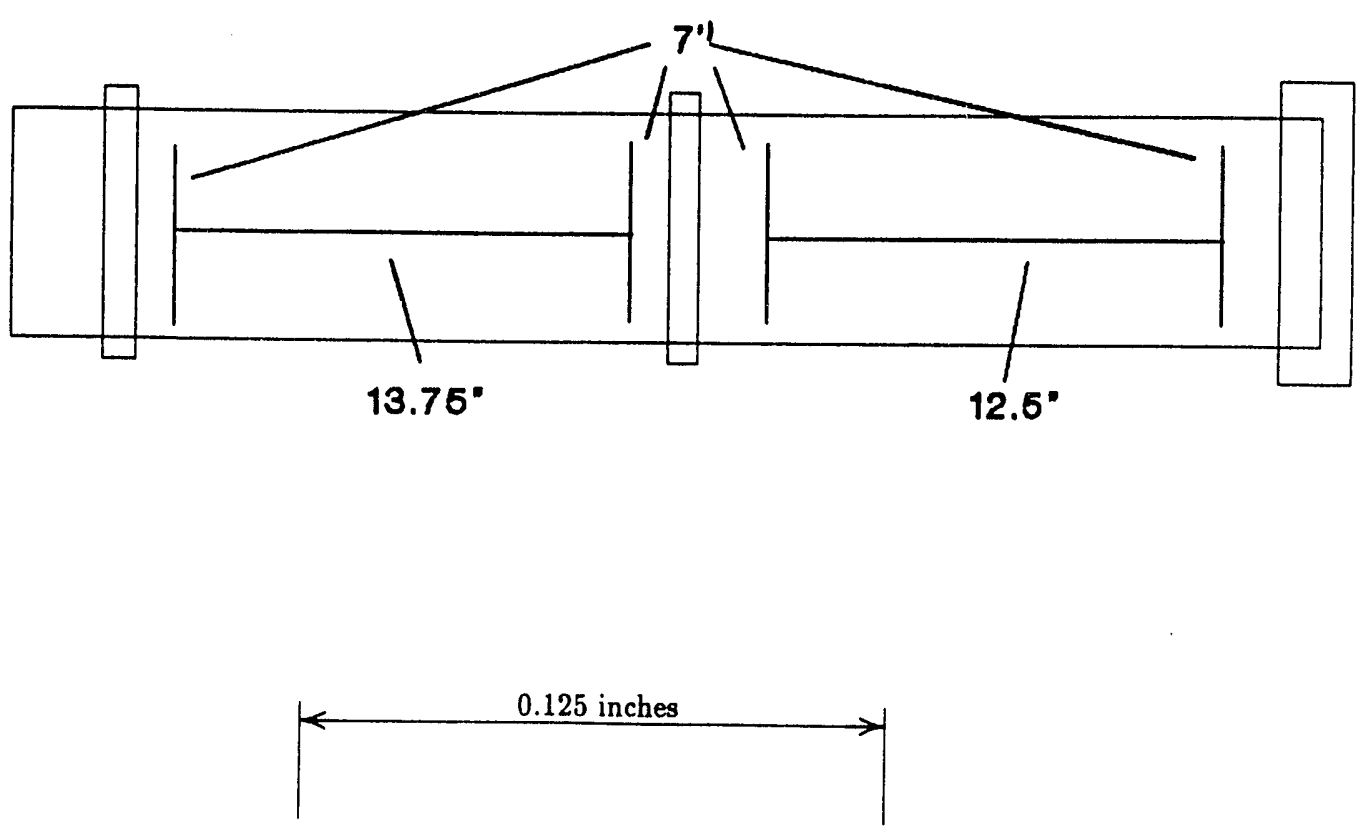

$\mathrm{D}=0.0478$ inches

布 $=0.25 \mathrm{D}=0.012$ inches

Fig. 8. Two score patterns and the cross section of the score. 


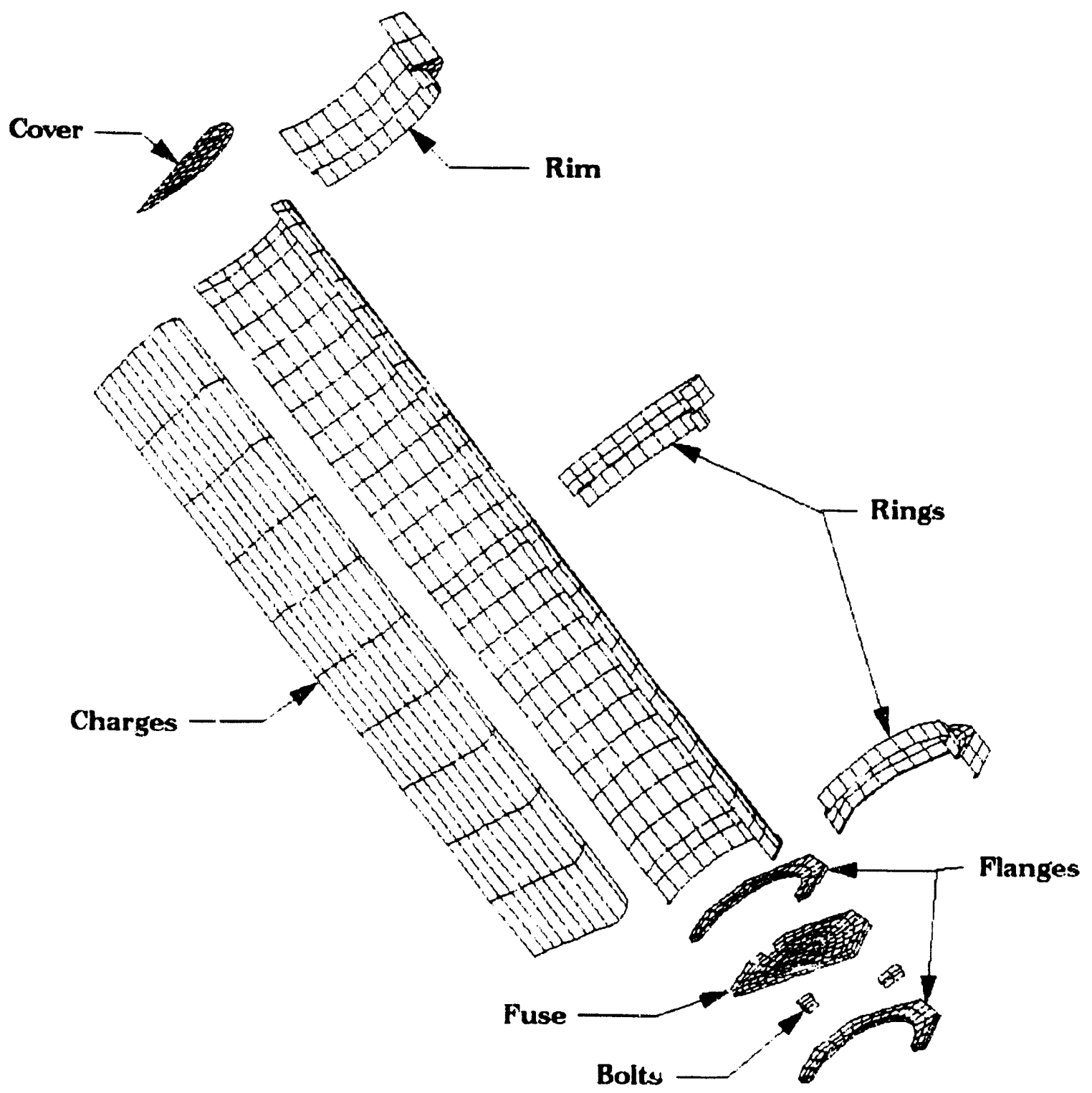

Fig. 9. Picatinuy IM (PA103) 7-ft free-fall impact model. 


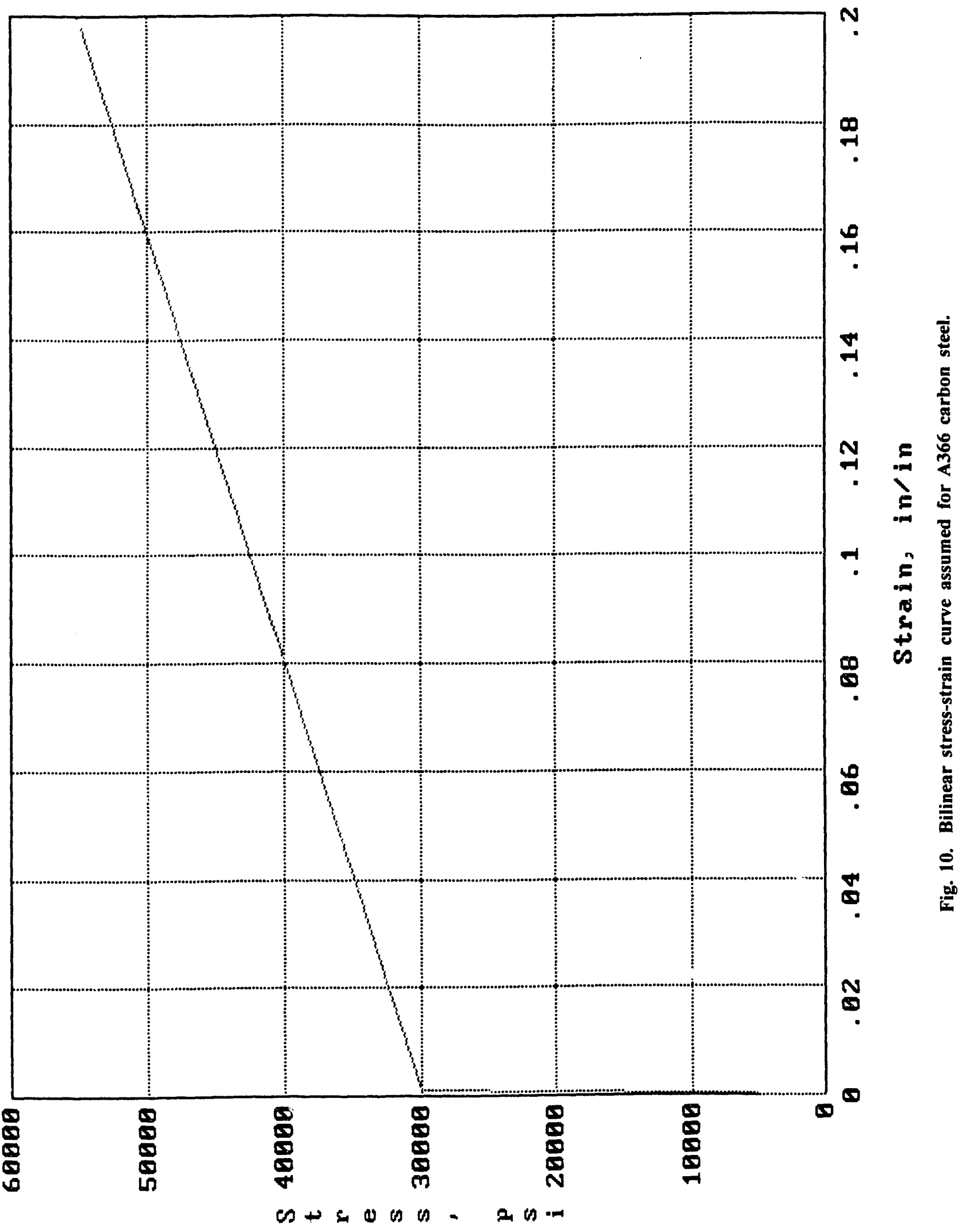




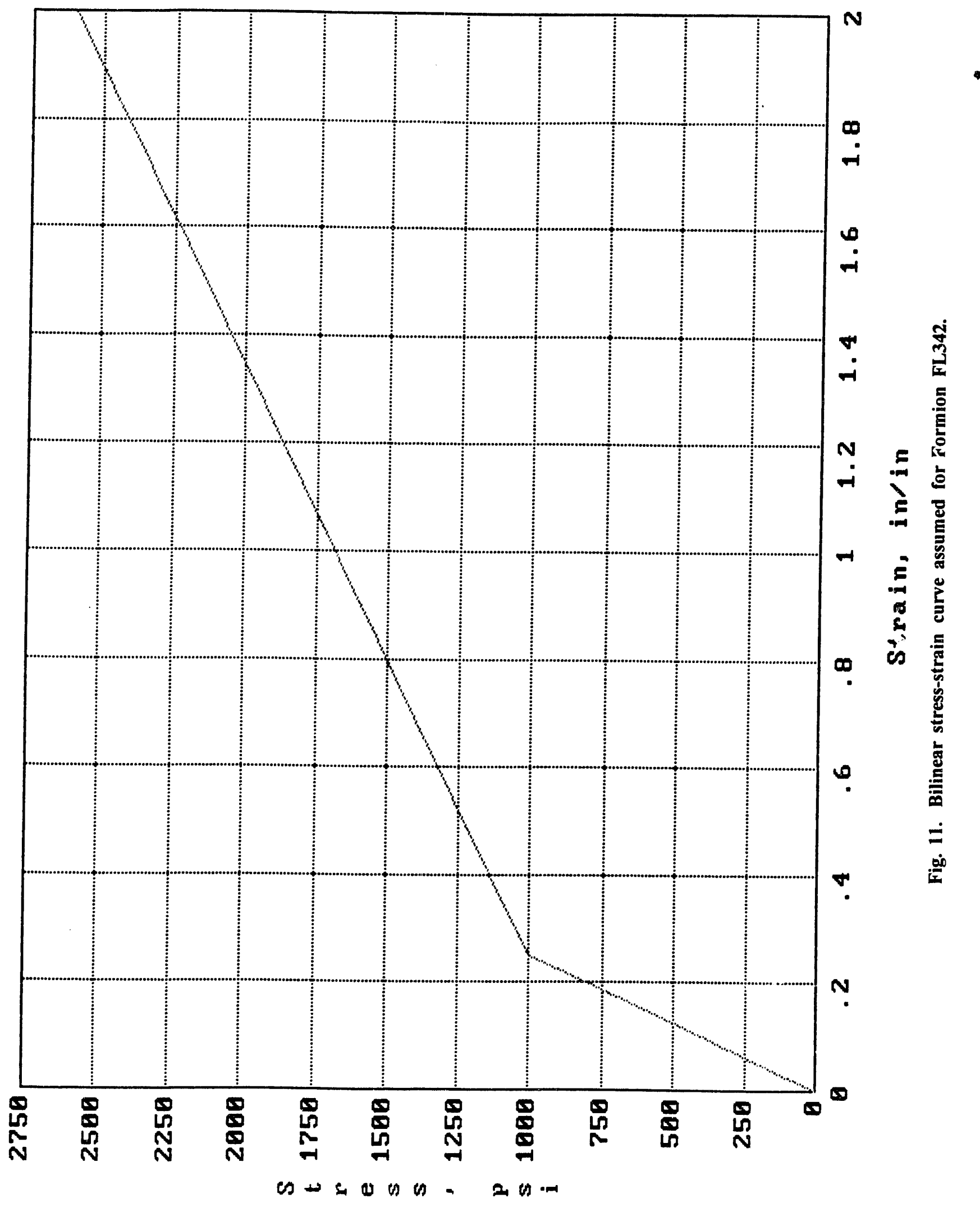




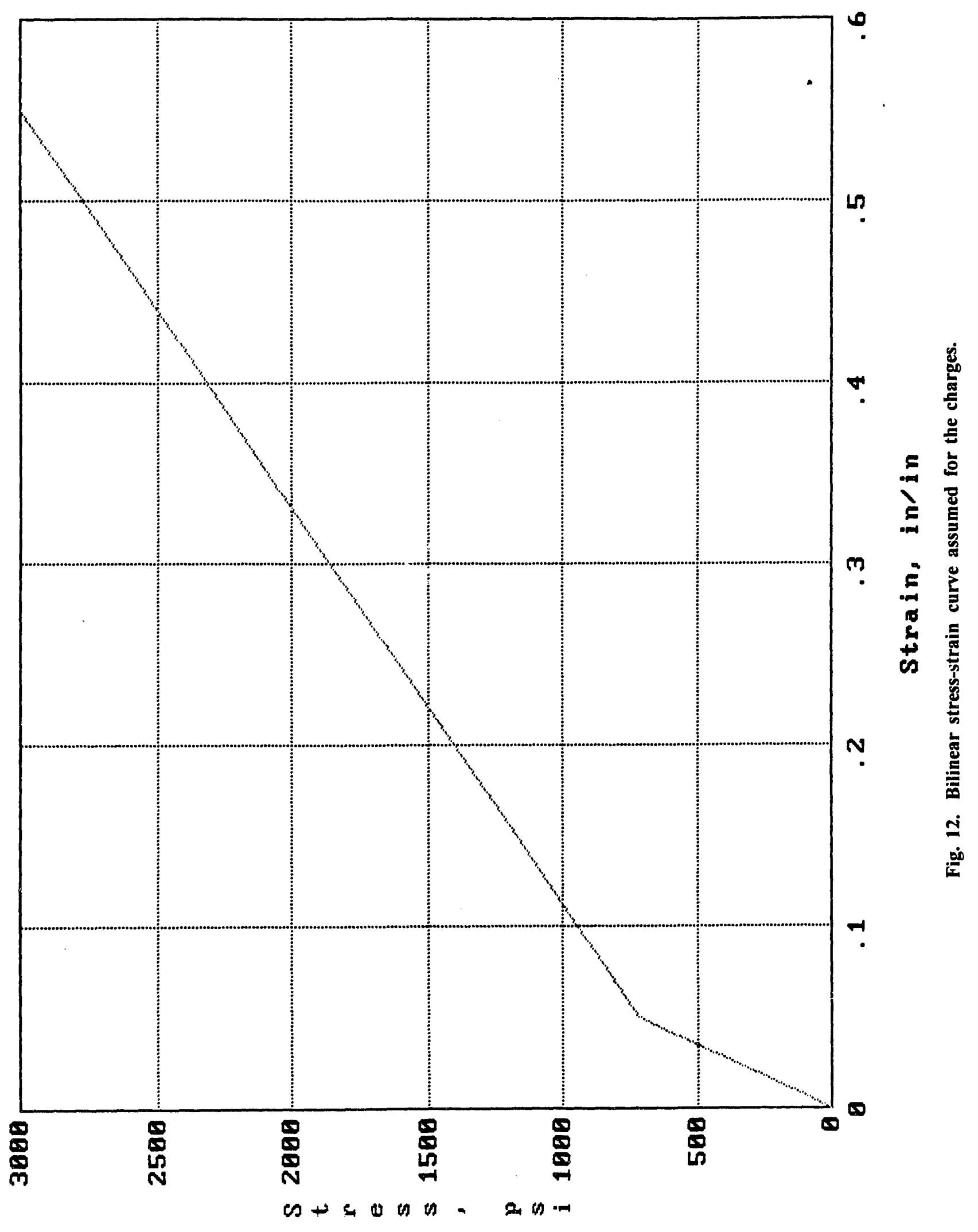


Piratinny IM - endB - 3/9/93

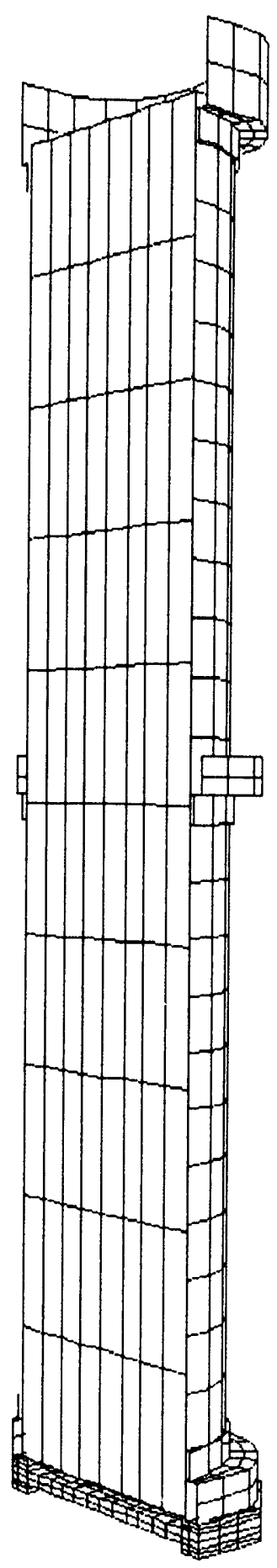

Fig. 13. End drop initial model. 


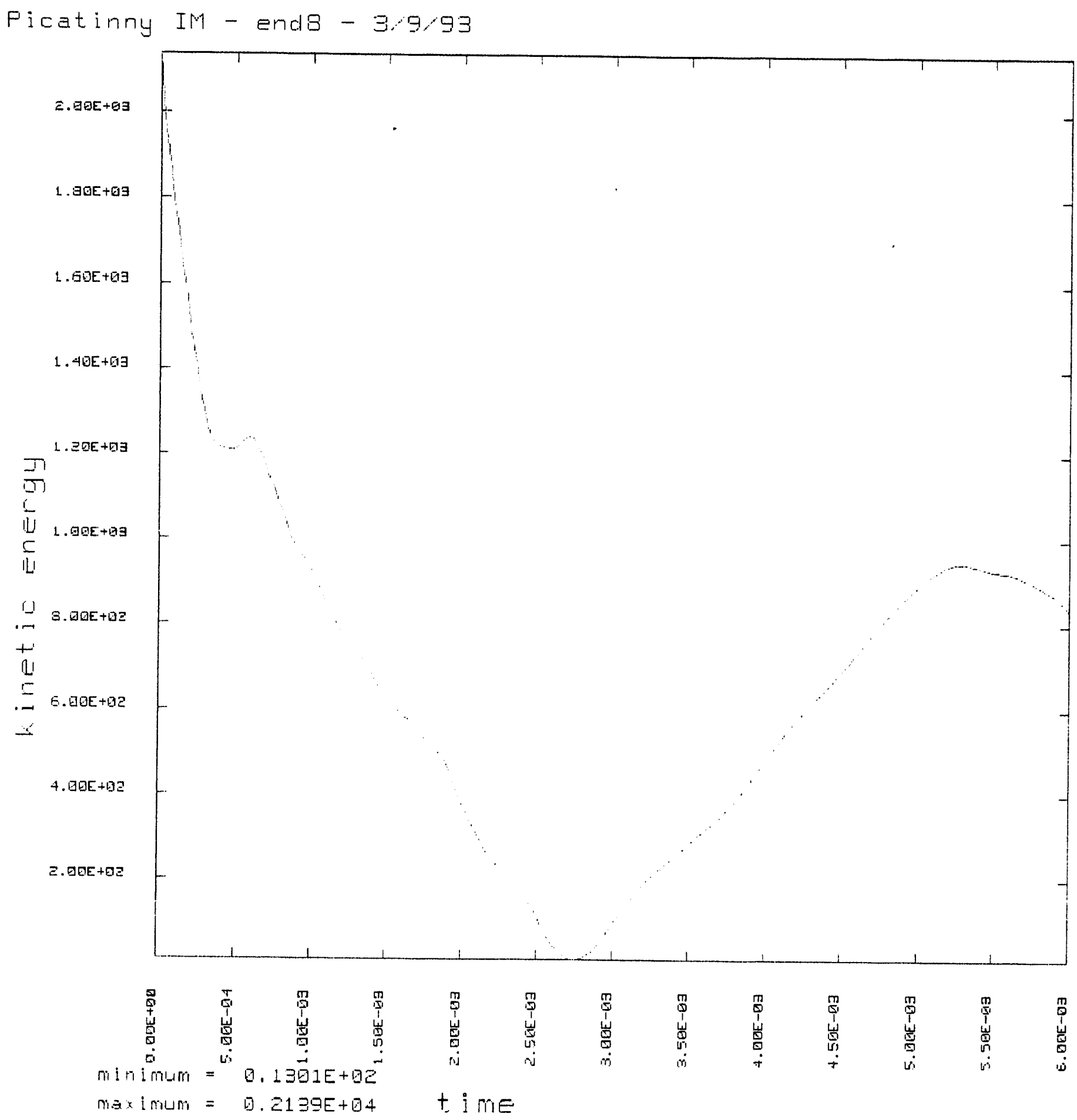

Fig. 14. Kinetic energy time history for the end impact. 

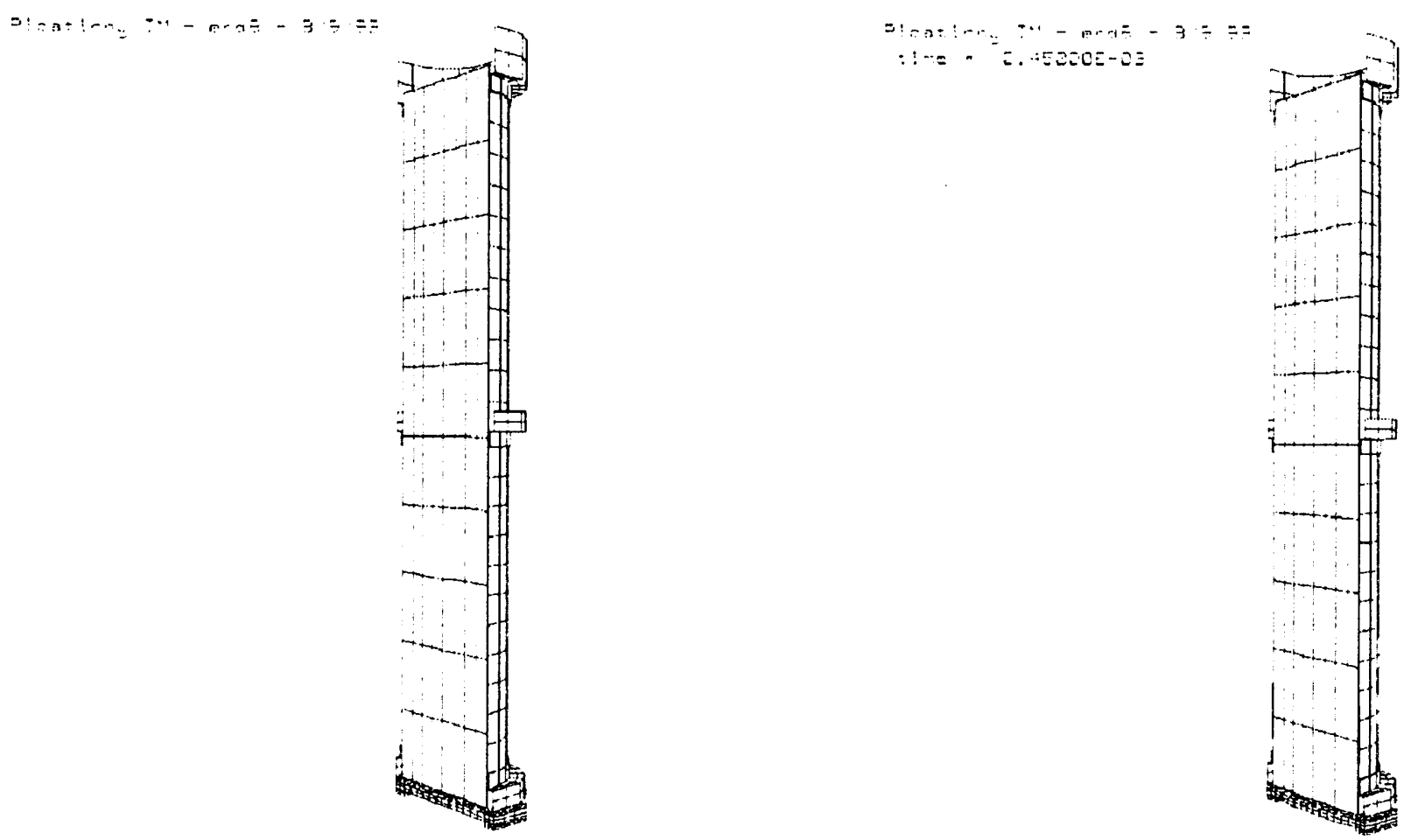

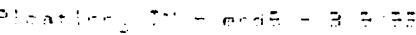

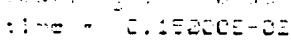
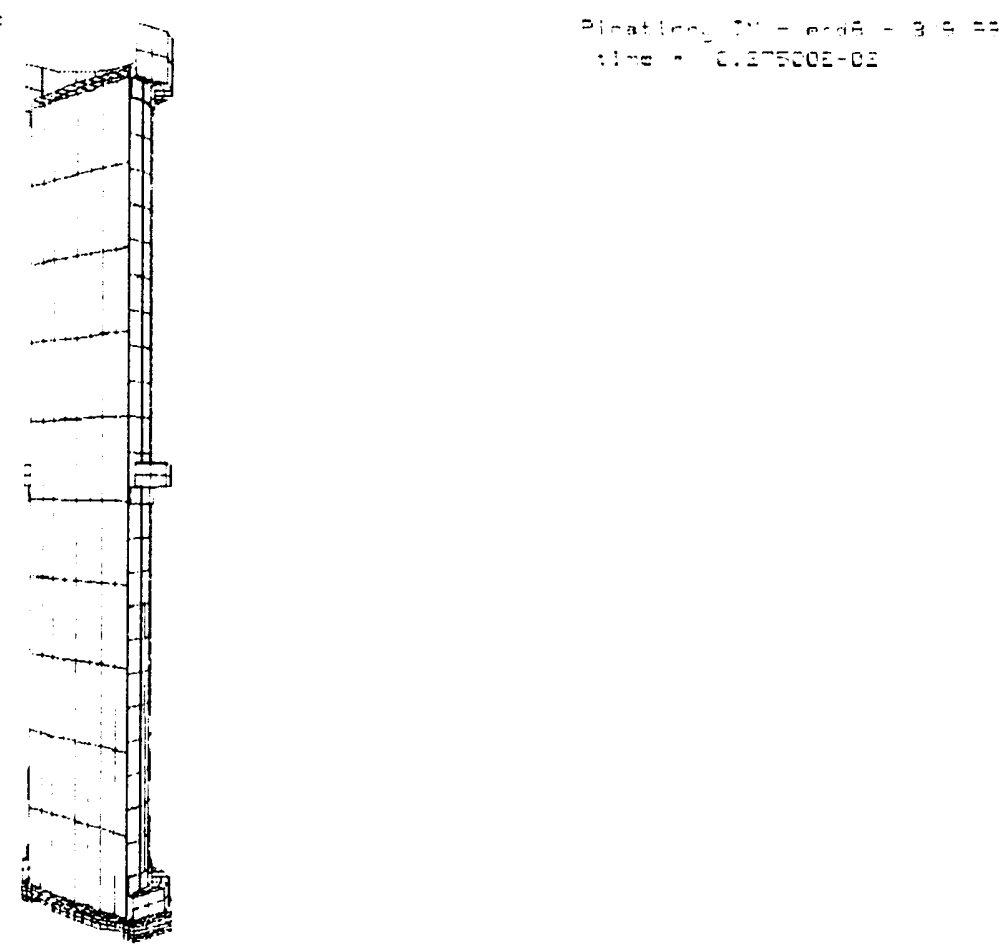

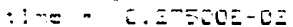

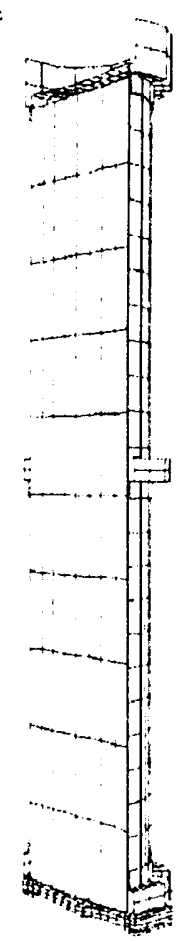

Fig. 15. Configuration of the container assembly at various times during the end drop impact. 

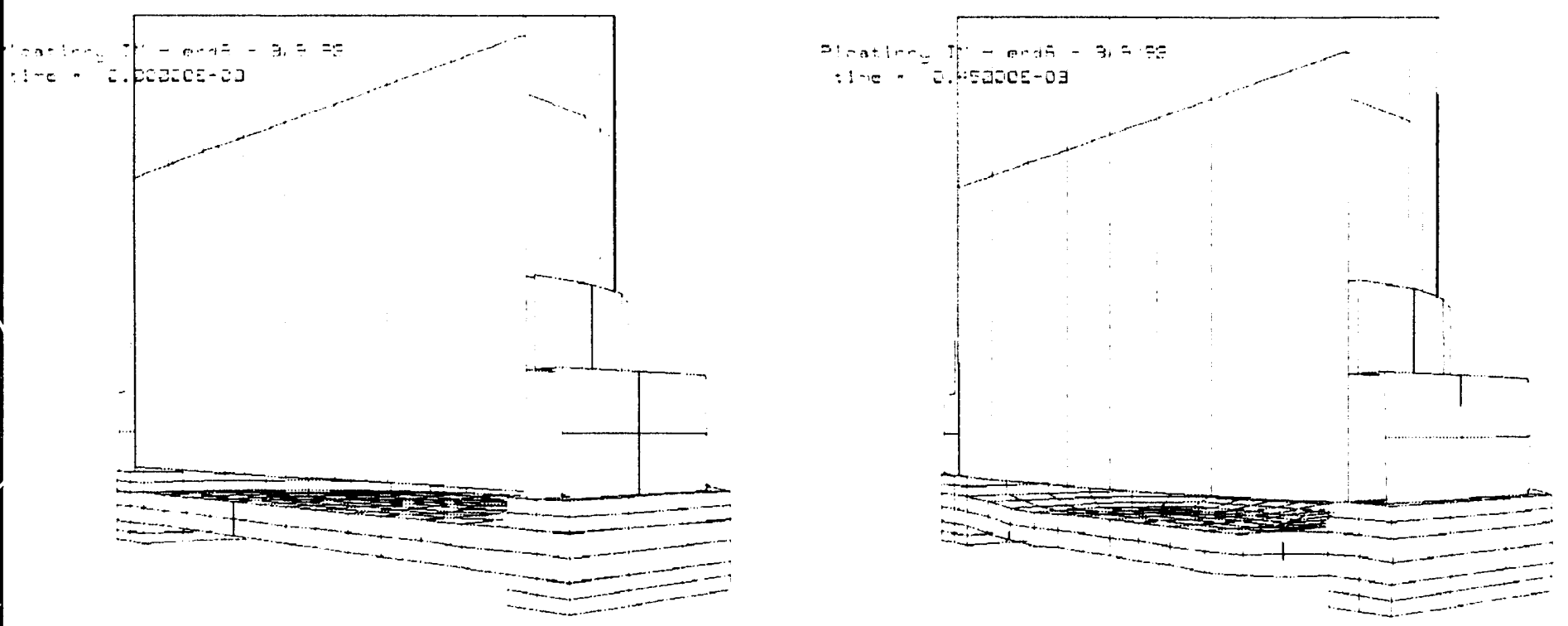

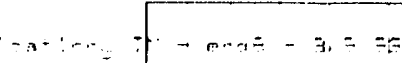
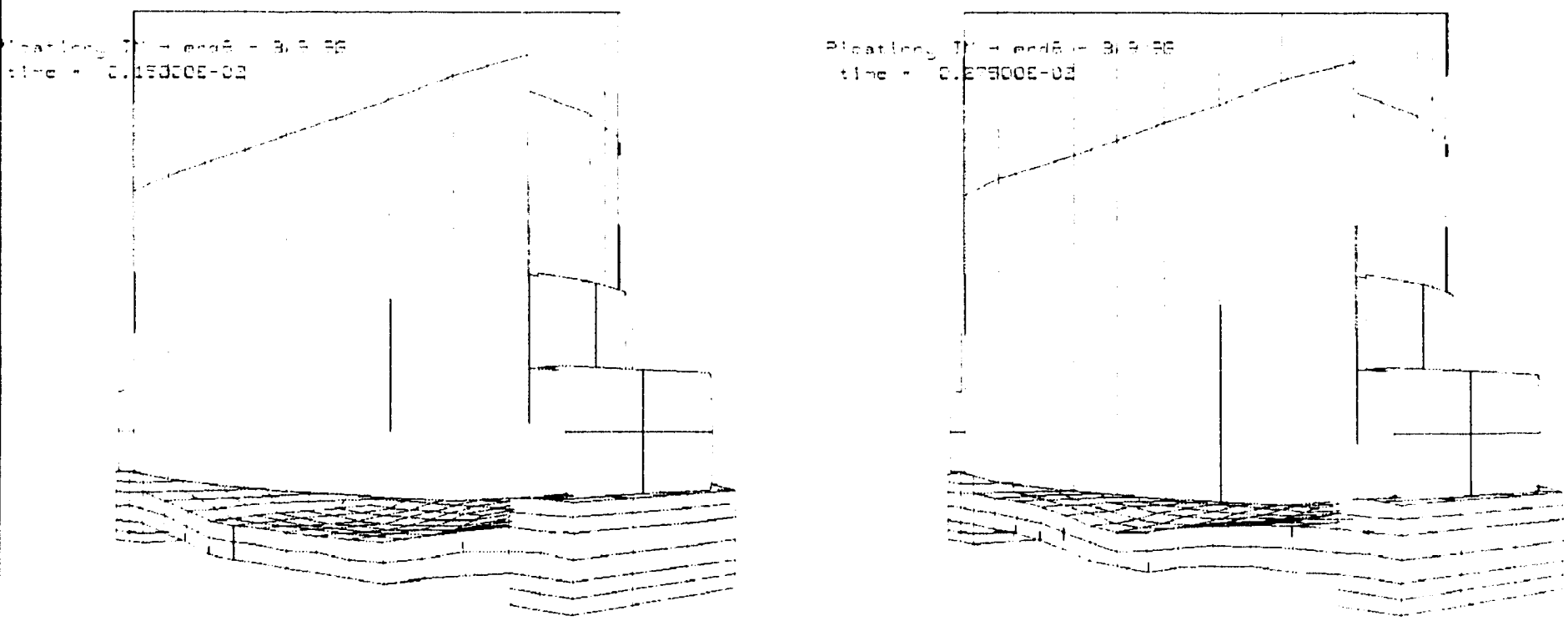

Fig. 16. Configuration of the impacting fuse end of the container at various times during the end impact. 


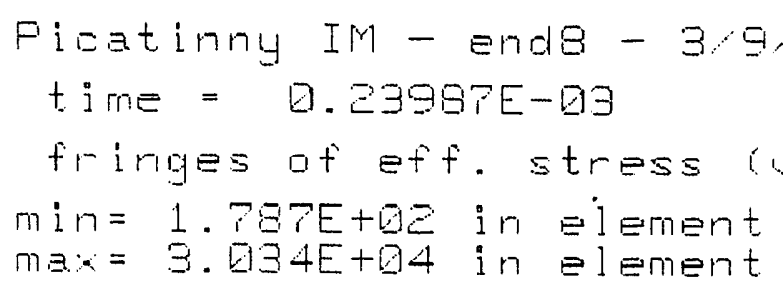

9,93

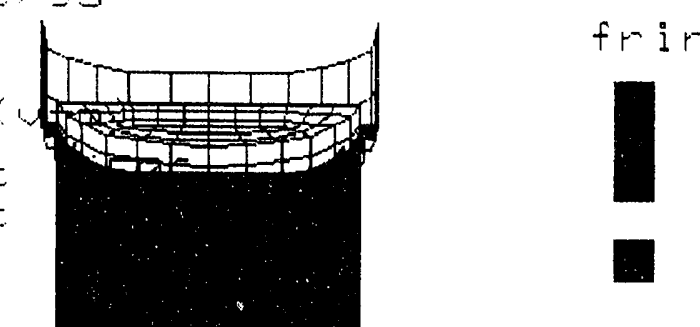

ge levels 4. $804 \mathrm{E}+03$ 1. $Q \square \square E+Q 4$ 1. $53 \mathrm{BE}+\mathrm{Q} 4$ 2. $05 \mathrm{DE}+04$ 2. $570 E+04$
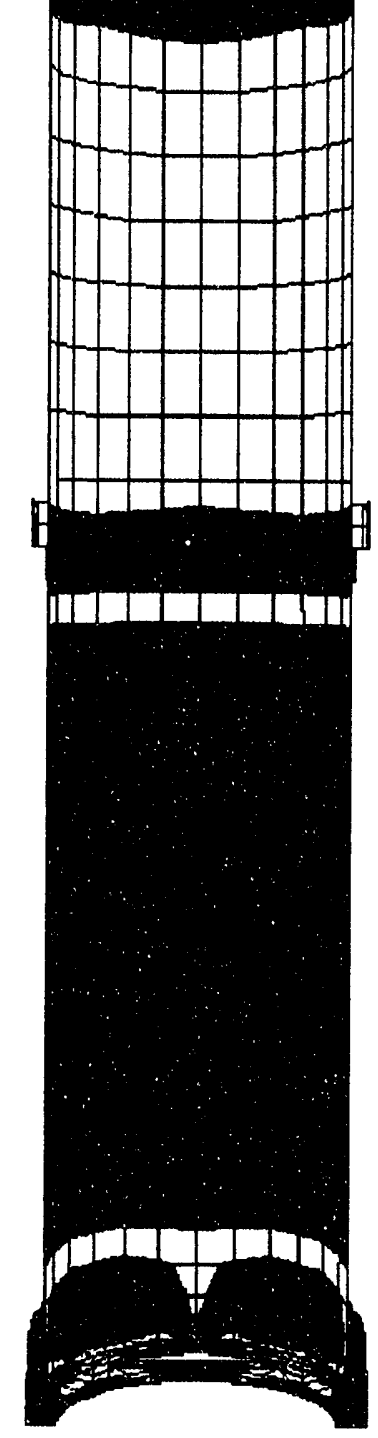

Fig. 17. Contours of effective stress in the body at time $=2.3987 \times 10^{-4} \mathrm{~s}$. 


$$
\begin{aligned}
& \text { Firatinny IM - endB - 39.93 } \\
& \text { time = Q.2398TE-日9 } \\
& \text { fringes of z-stress }
\end{aligned}
$$

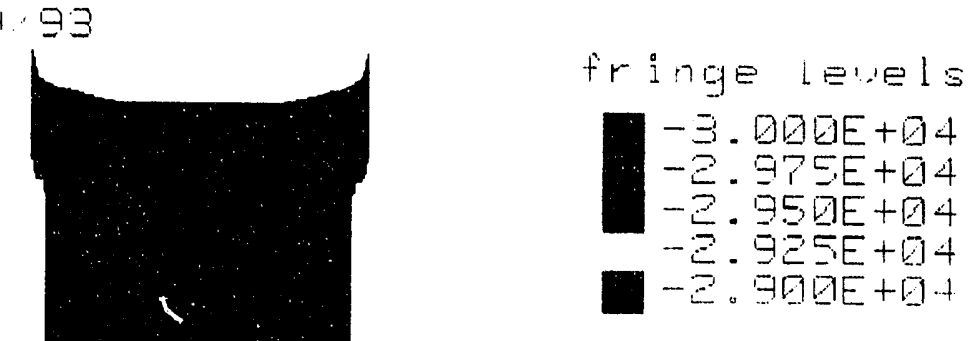

Fig. 18. Contours of maximum axial compressive stress in the vicinity of the lower score pattern. 
Picatinny IM - endB - 3993

time = 0.83982E-03

fringes of z-stress

min $=-4.364 E+Q 3$ in element

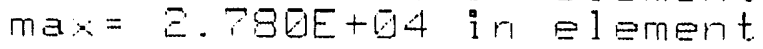

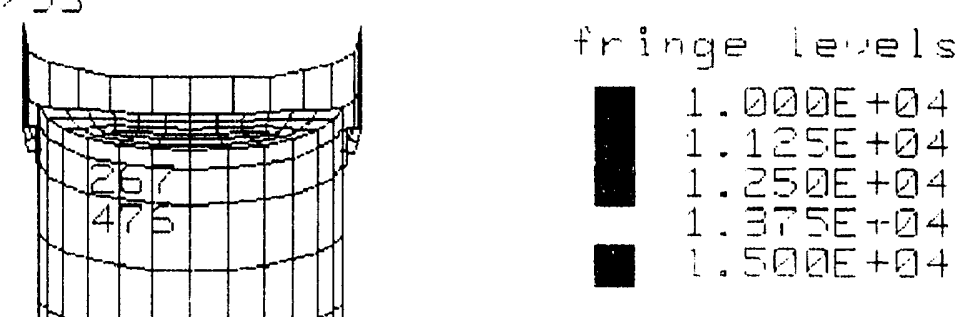

Fig. 19. Contours of maximum axial tension stress in the vicinity of the lower score pattern. 
Picatinny IP - endB - 39
time $=0.44987 E-09$
fringes of eff.plastic

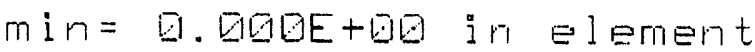
max $=1.421 E-\theta 2$ in element

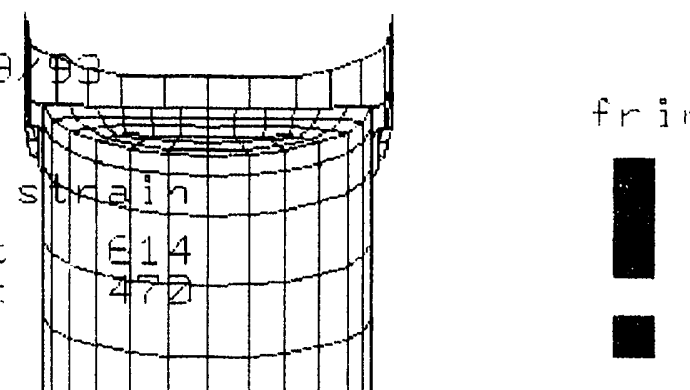

fringe lewels 2.179E-D政 4. $642 \mathrm{E}-\mathrm{QB}$ 7. $105 E-03$ 9. $568 \mathrm{BE}-\mathrm{QB}$ 1.2Q日E-日E

Fig. 20. Contours of effective plastic strain in the body. 


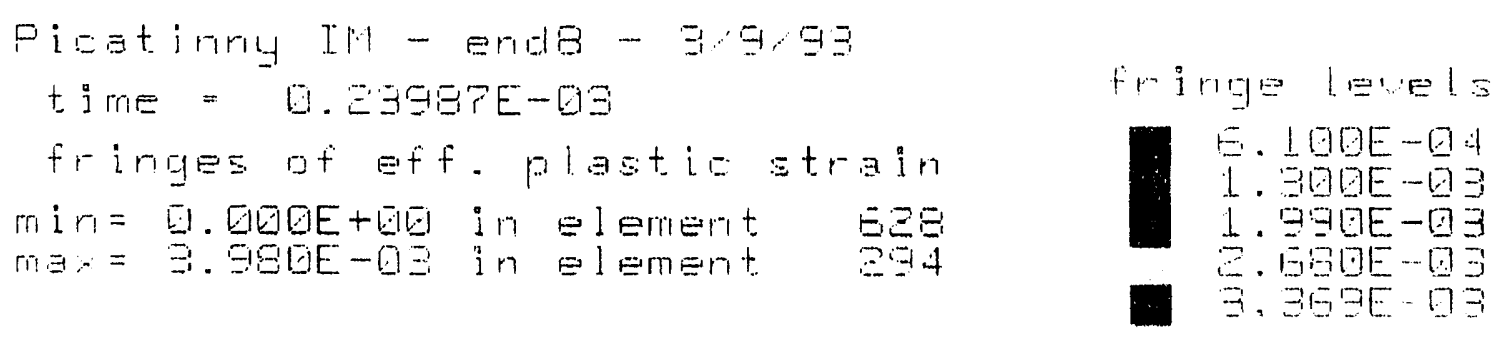

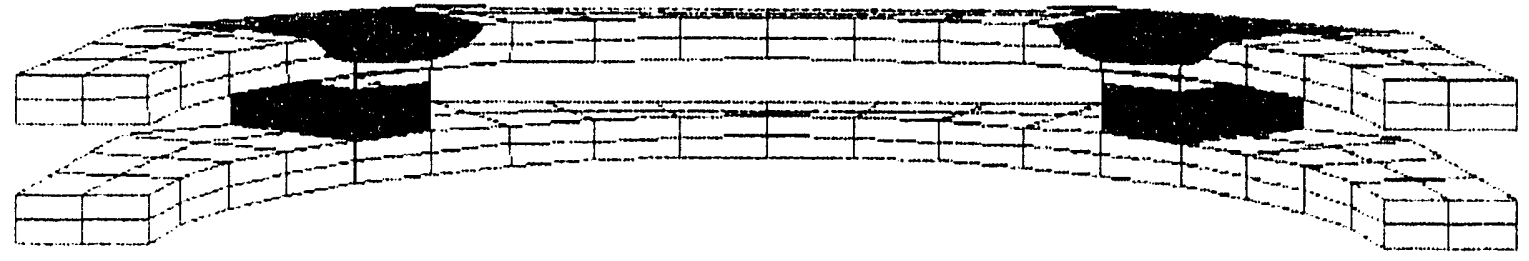

Fig. 21. Contours of effective plastic strain in the flanges and bolts. 
Picatinny IM - side1 - 3/11/93

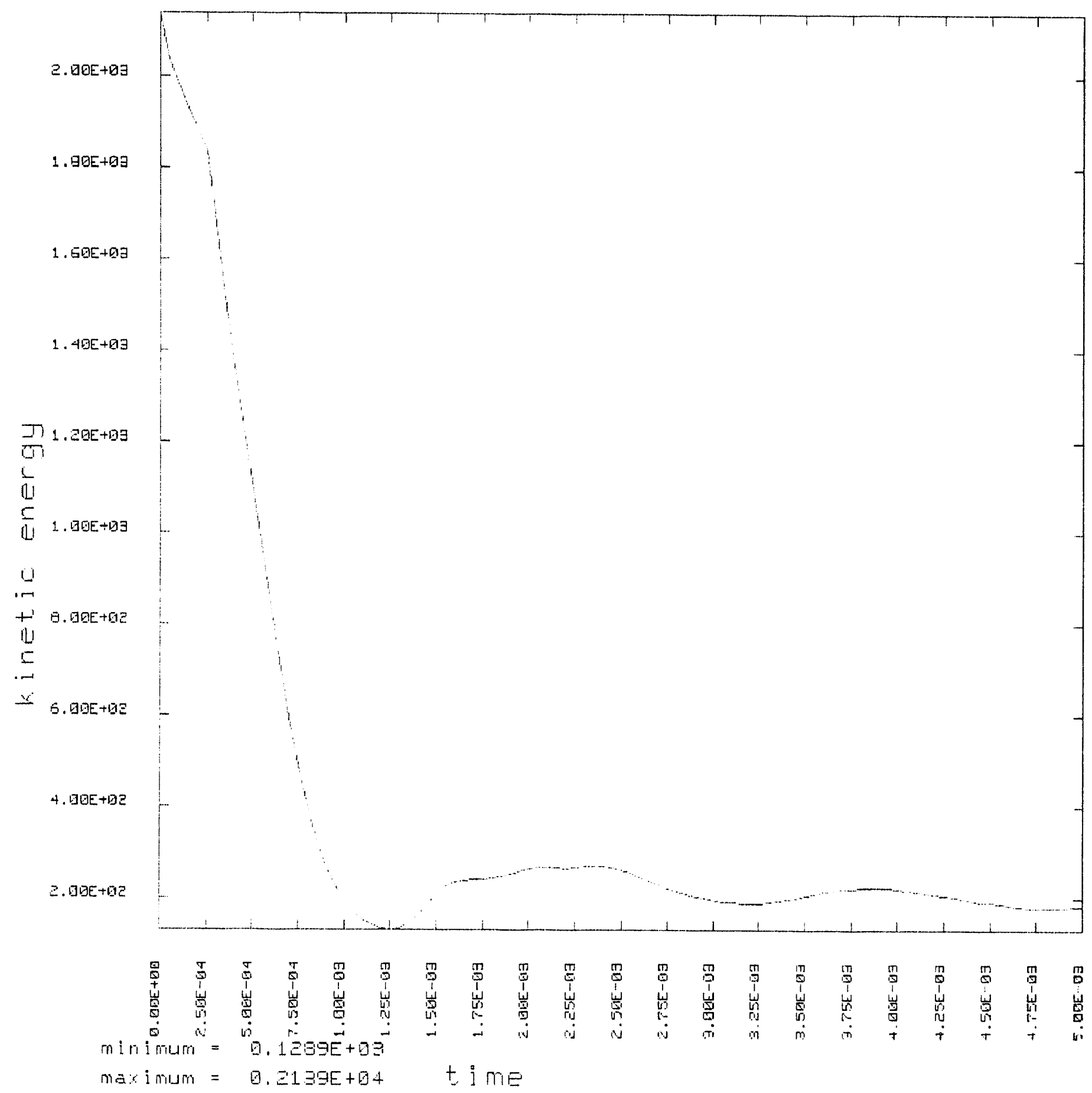

Fig. 22. Kinetic energy time history for the side drop. 

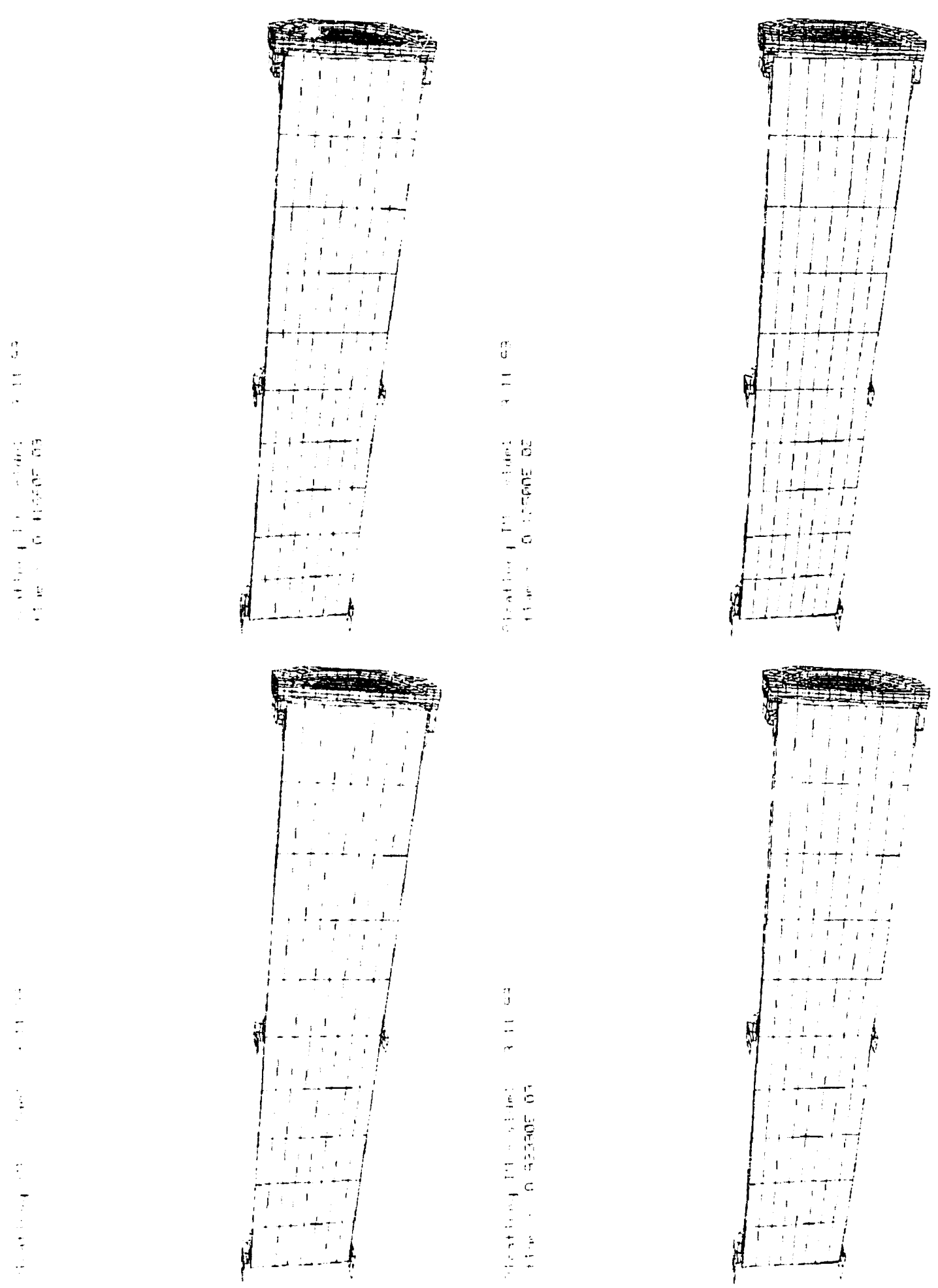

हैं 


$$
\begin{aligned}
& \text { Pigatimry IM -- sidel - } 31193 \\
& \text { time = B.1ESDGE-EZ } \\
& \text { finges of eff. stress }, \cdots-m \text { ! }
\end{aligned}
$$

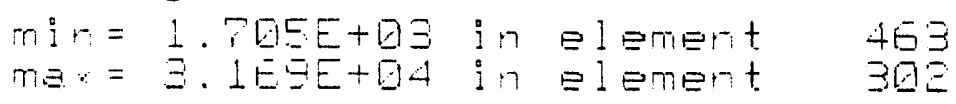

$$
\begin{aligned}
& \text { iringe iewels }
\end{aligned}
$$

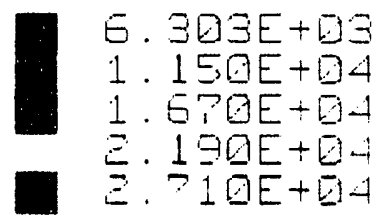

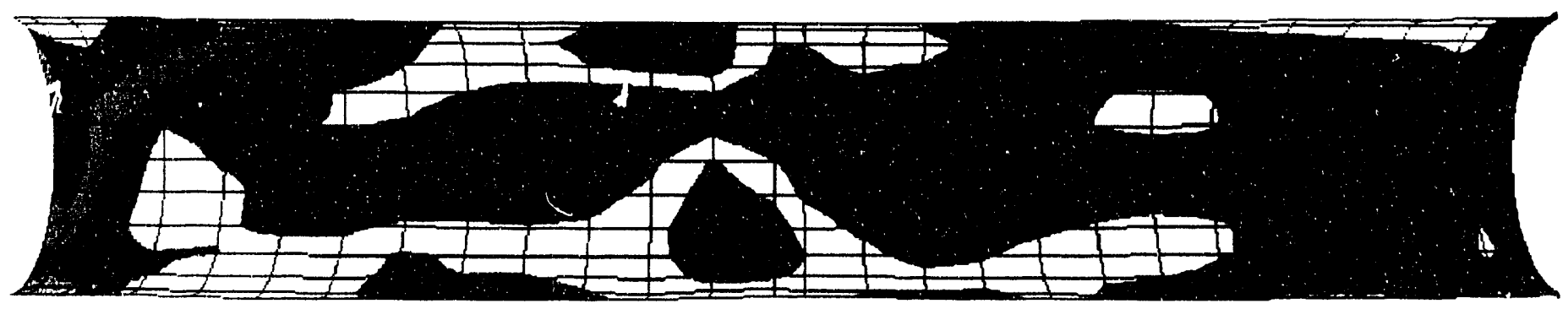

Fig. 24. Contours of maximum effective stress in the body for the side drop. 


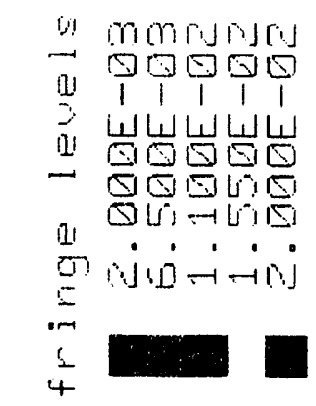

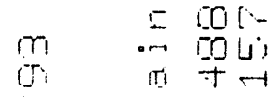

$$
\begin{aligned}
& \Rightarrow \quad+ \\
& \text { (n) } \quad \text { E } \\
& \begin{array}{l}
1+E \\
-1)
\end{array} \\
& \text { म) } \\
& \therefore \quad I \quad= \\
& \text { ज! } \Omega \text {, वाँ }
\end{aligned}
$$

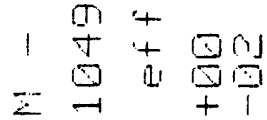

$$
\begin{aligned}
& \text { Ð } \\
& \text { I }
\end{aligned}
$$

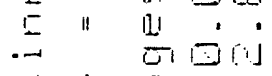

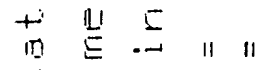

$$
\begin{aligned}
& \begin{array}{l}
0+5 \\
\square+\square
\end{array}
\end{aligned}
$$

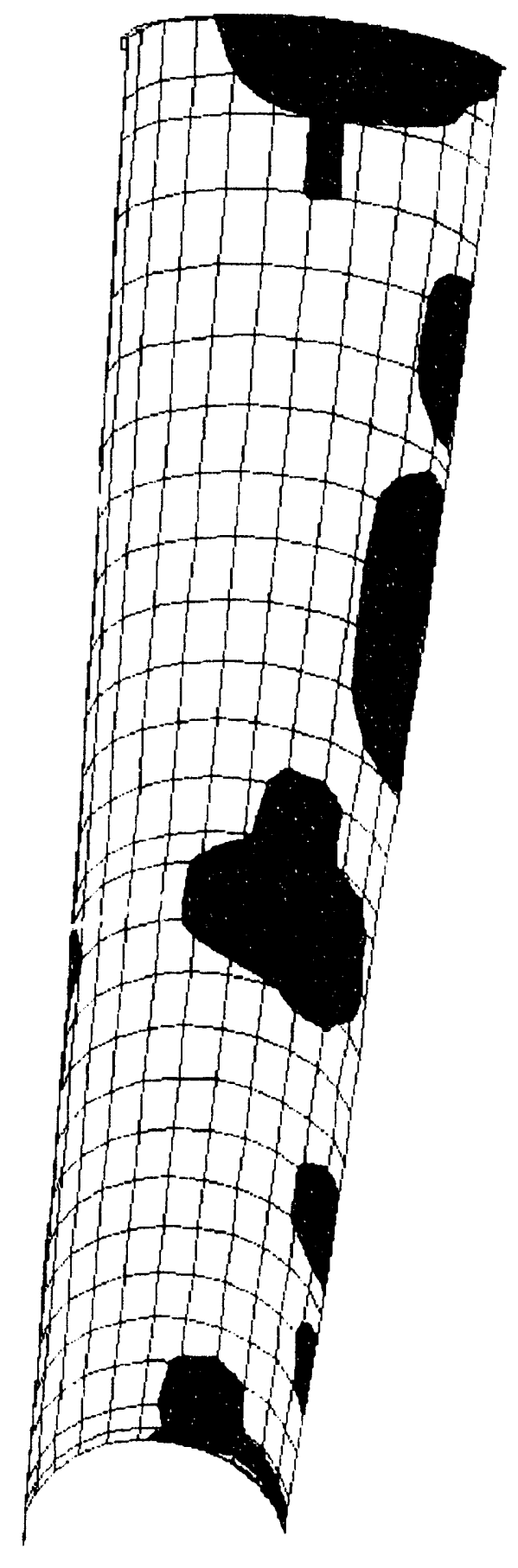

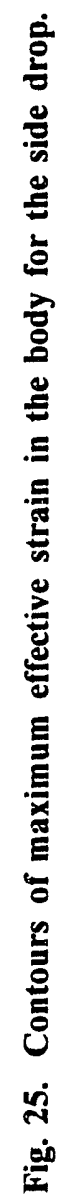



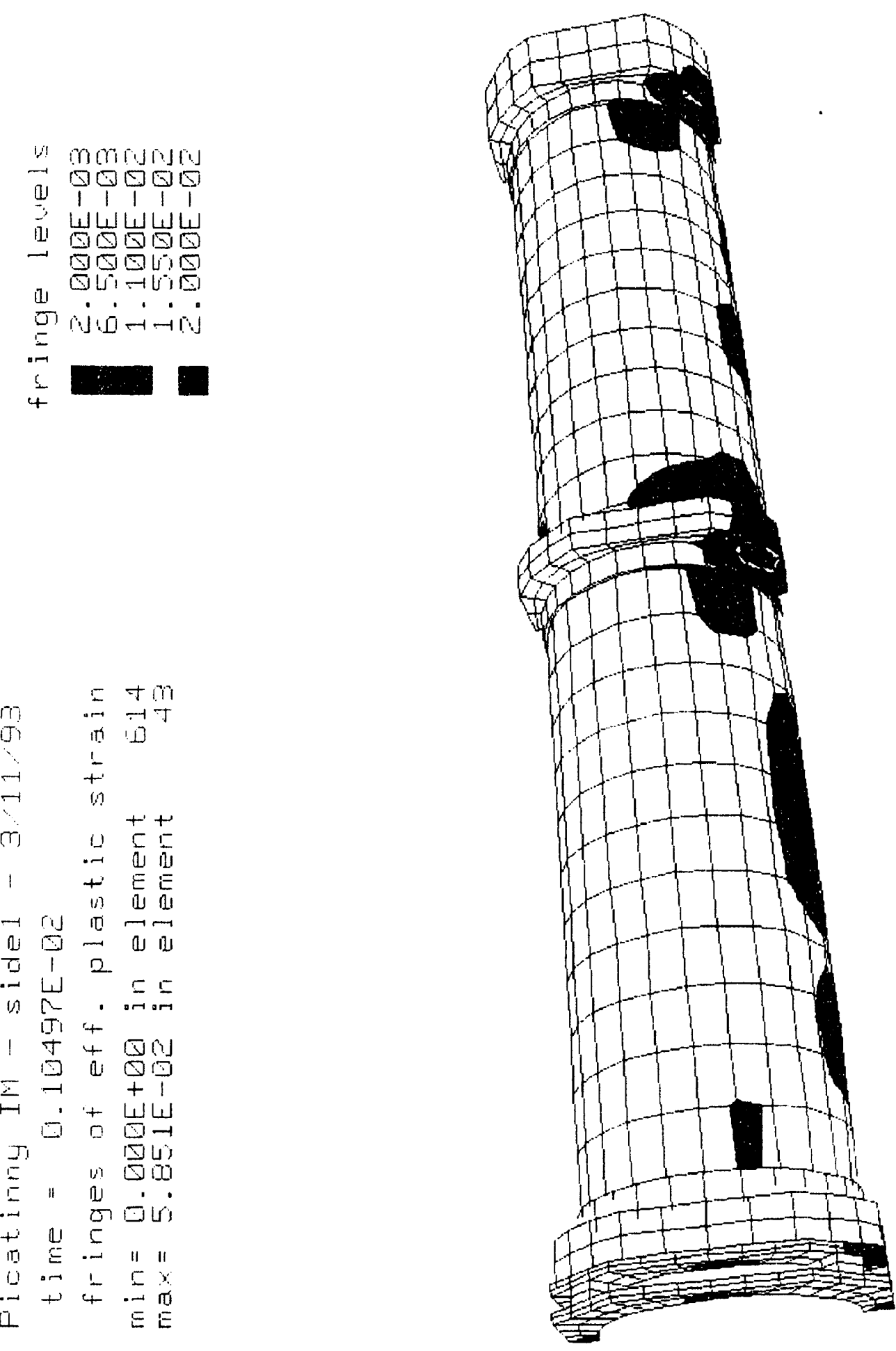

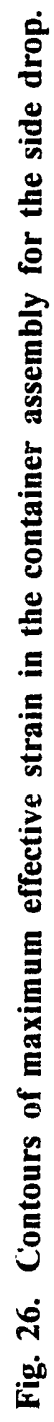




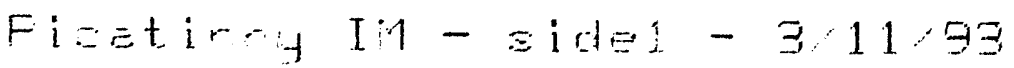

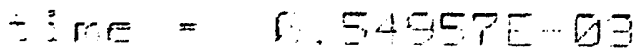

$$
\begin{aligned}
& \text { - lnges o eff. plastic atrain } \\
& \text { min= D. DOE +QO in Element EJE }
\end{aligned}
$$

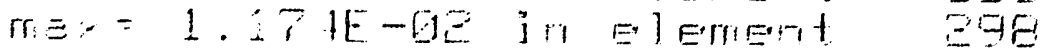

$$
\begin{aligned}
& \text { trirge } 1 \text { EN } \\
& \text { 1. } 900 E-93 \\
& \because 90 E-9= \\
& \exists,-4 C E-19=
\end{aligned}
$$

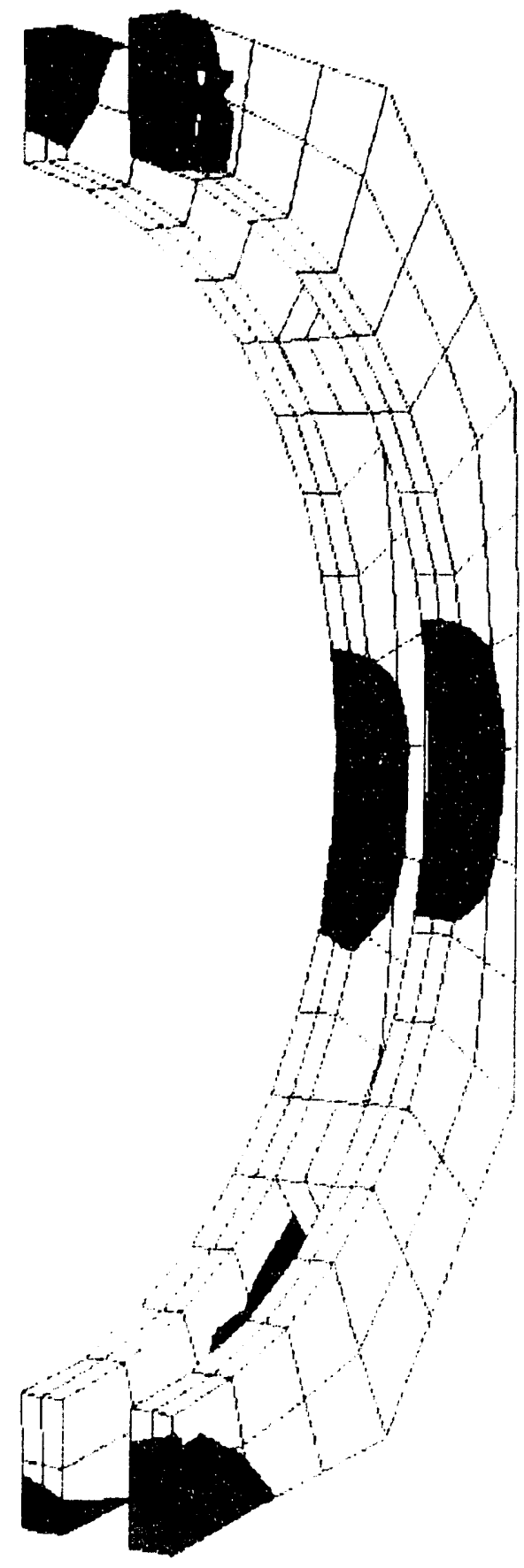

Fig. 27. Effective plastic strain in the flanges due to the side drop. 

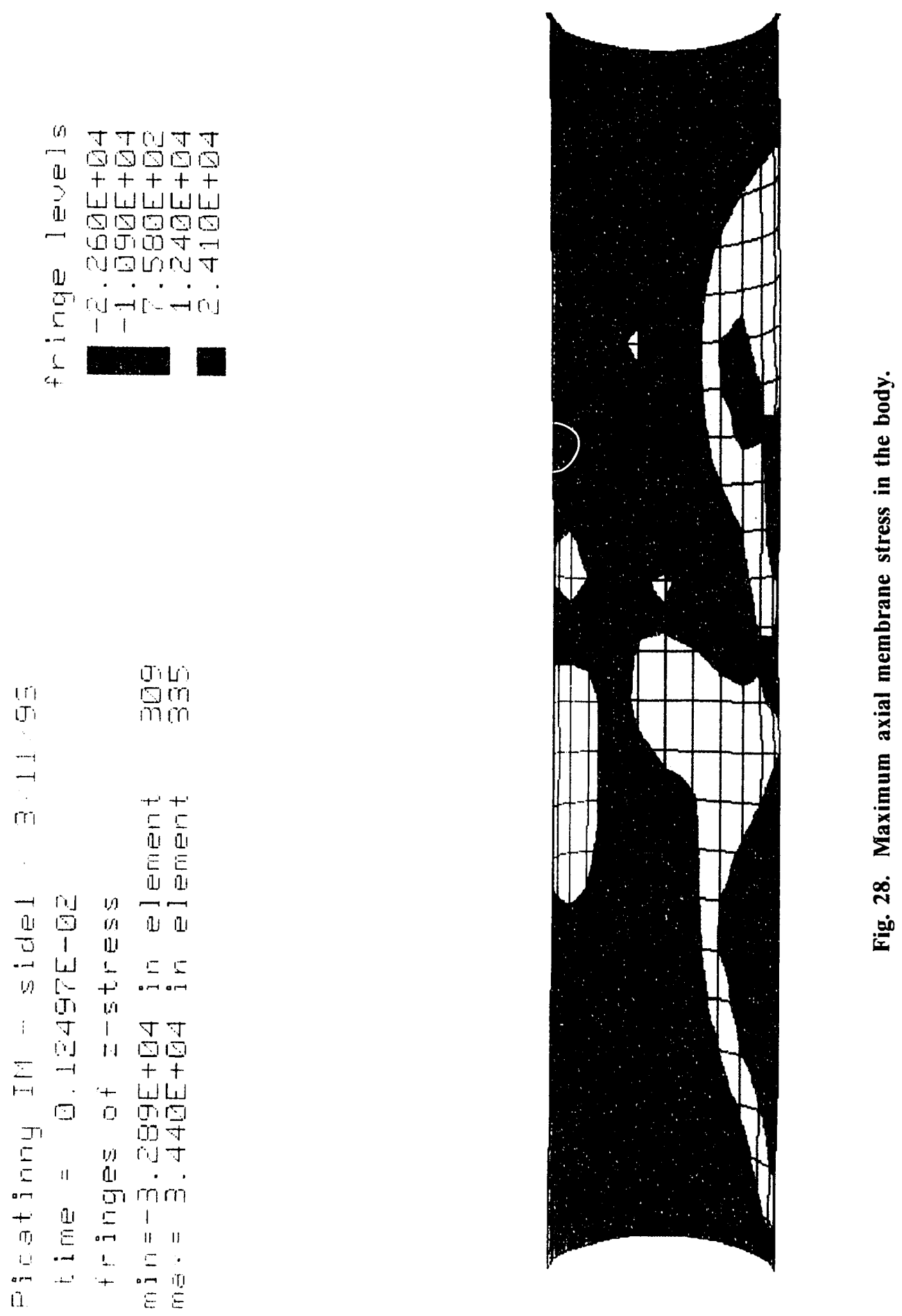

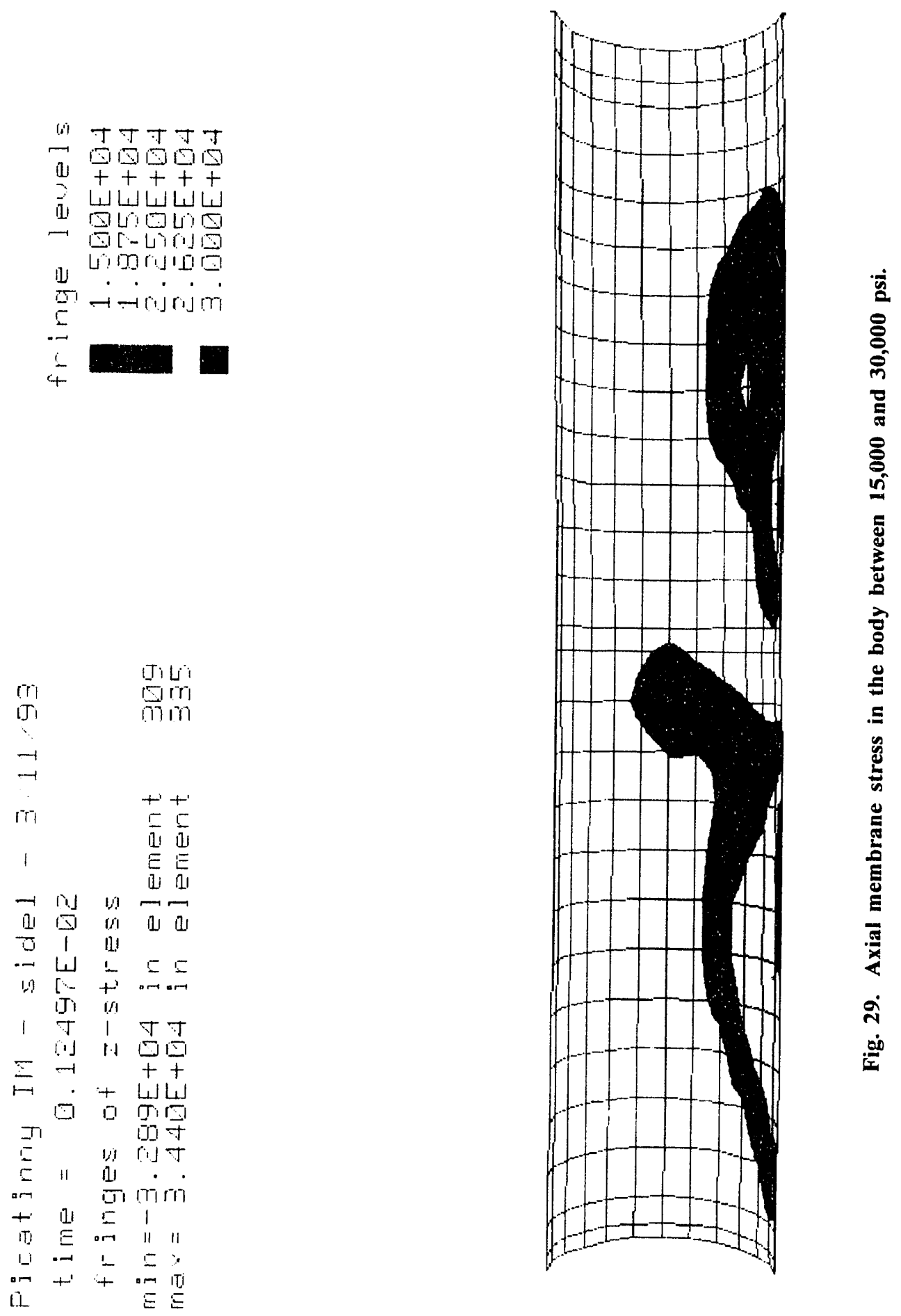
Picatinny IM - corner $3-3.12$

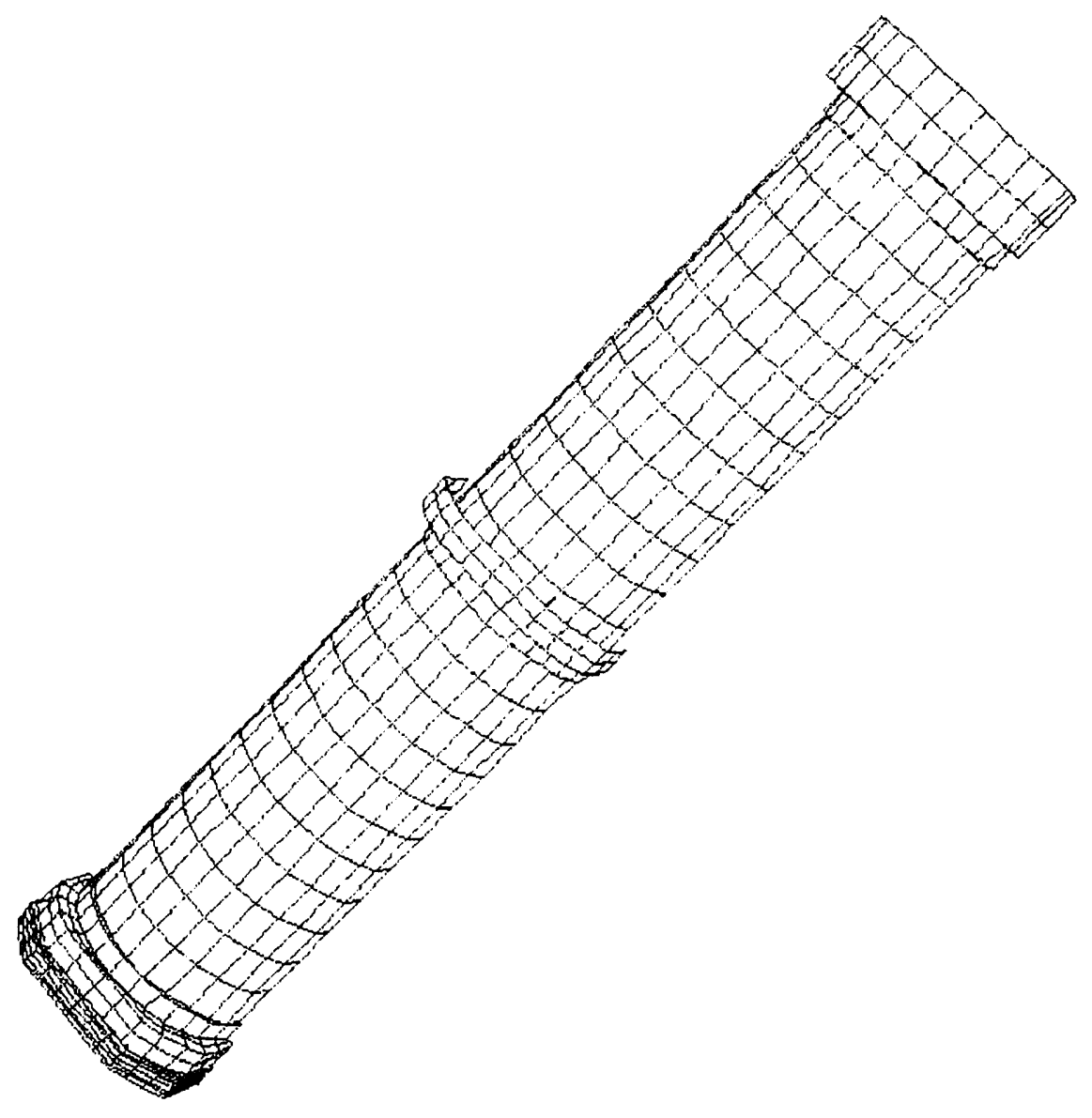

Fig. 30. Initial model configuration for the corner drop. 
Picatinny IM - aorner $\Xi-\exists: 12$

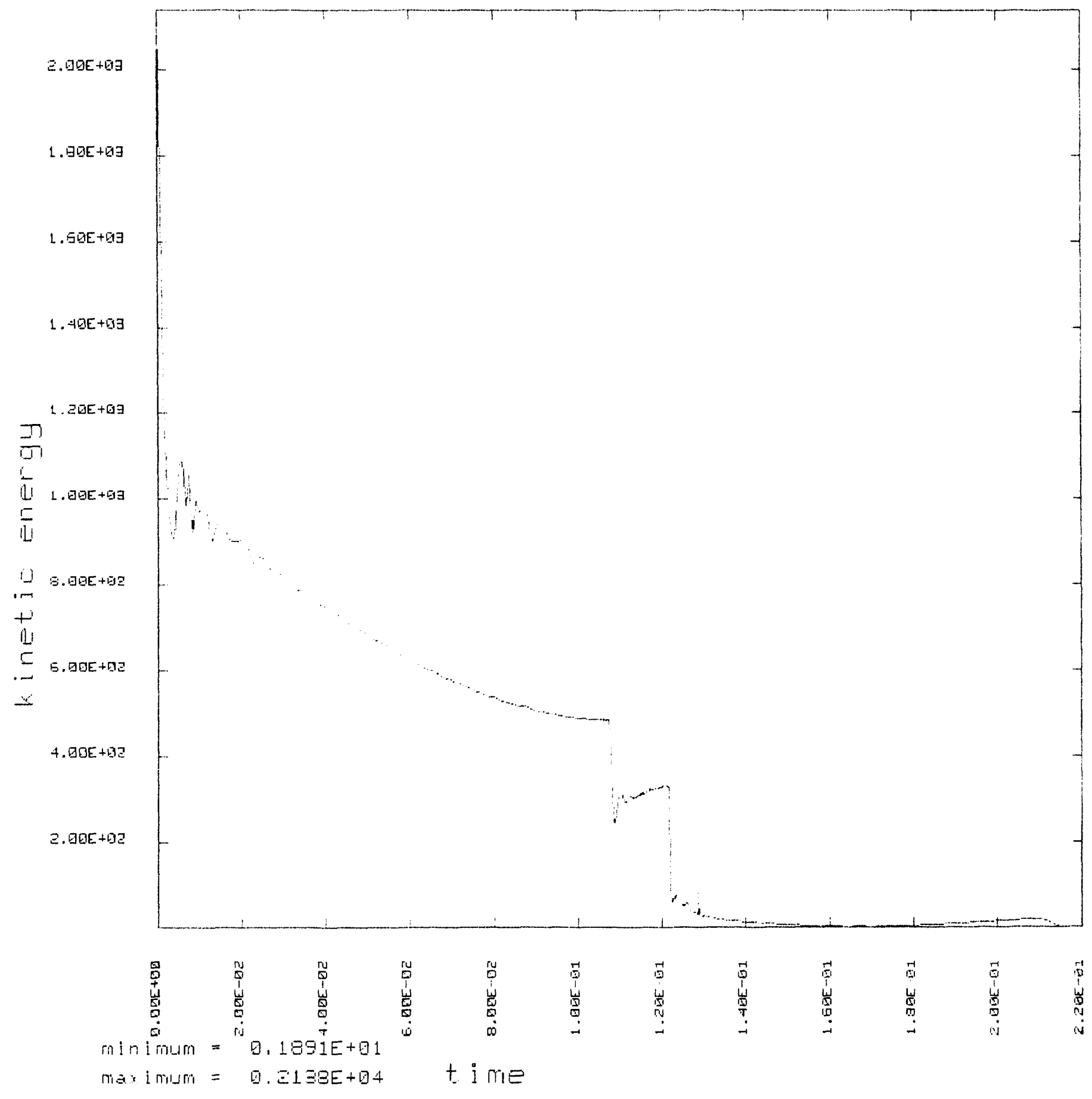

Fig. 31. Kinetic energy time history for the corner drop. 


$$
\begin{aligned}
& \text { Picatinny IM - earner } \Xi-3.12 \\
& \text { time }=0.40000 E-02
\end{aligned}
$$

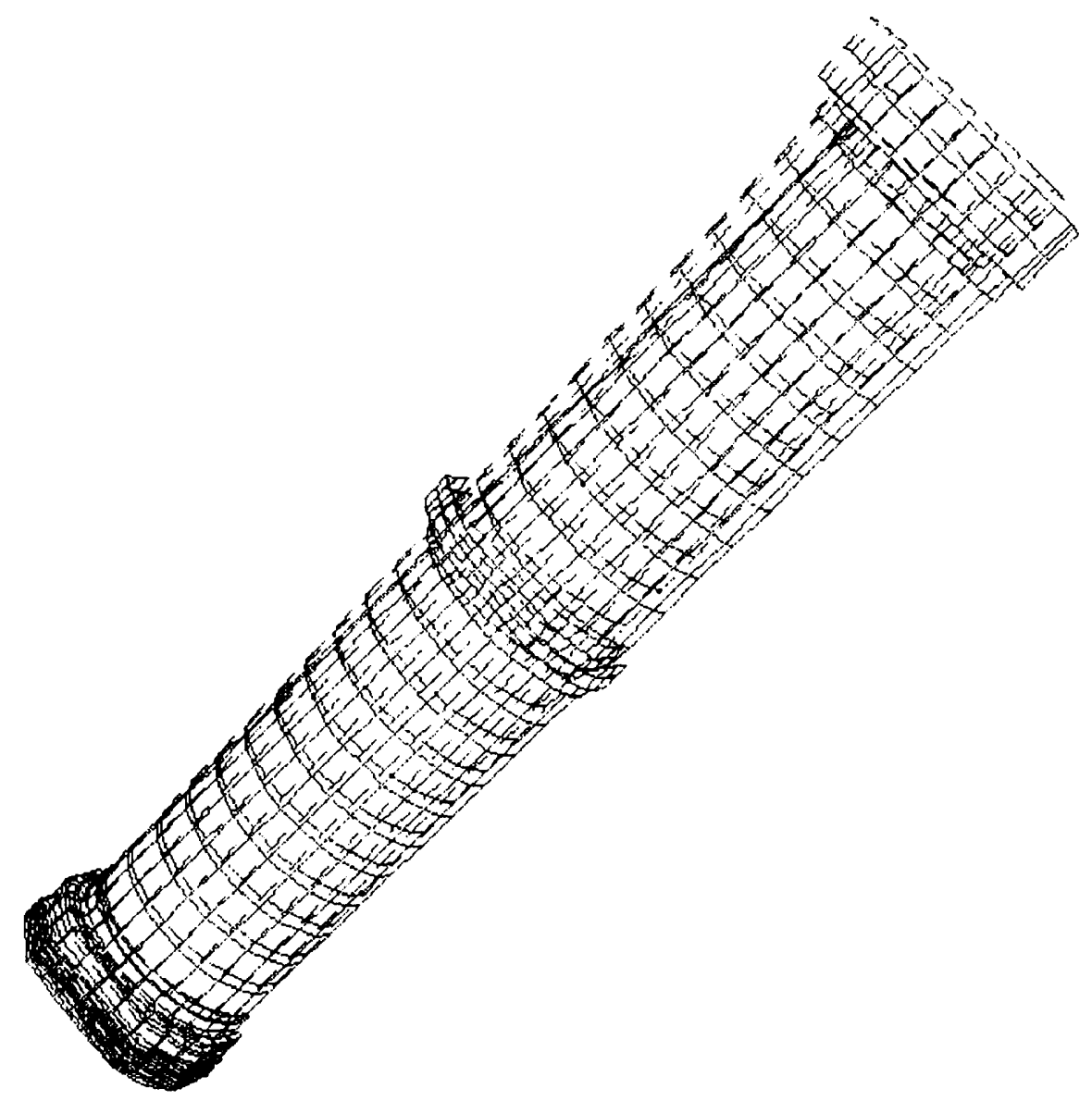

Fig. 32. Orientation of the container at $4.0 \times 10^{-3} \mathrm{~s}$ (dashed outline represents the original position). 
44

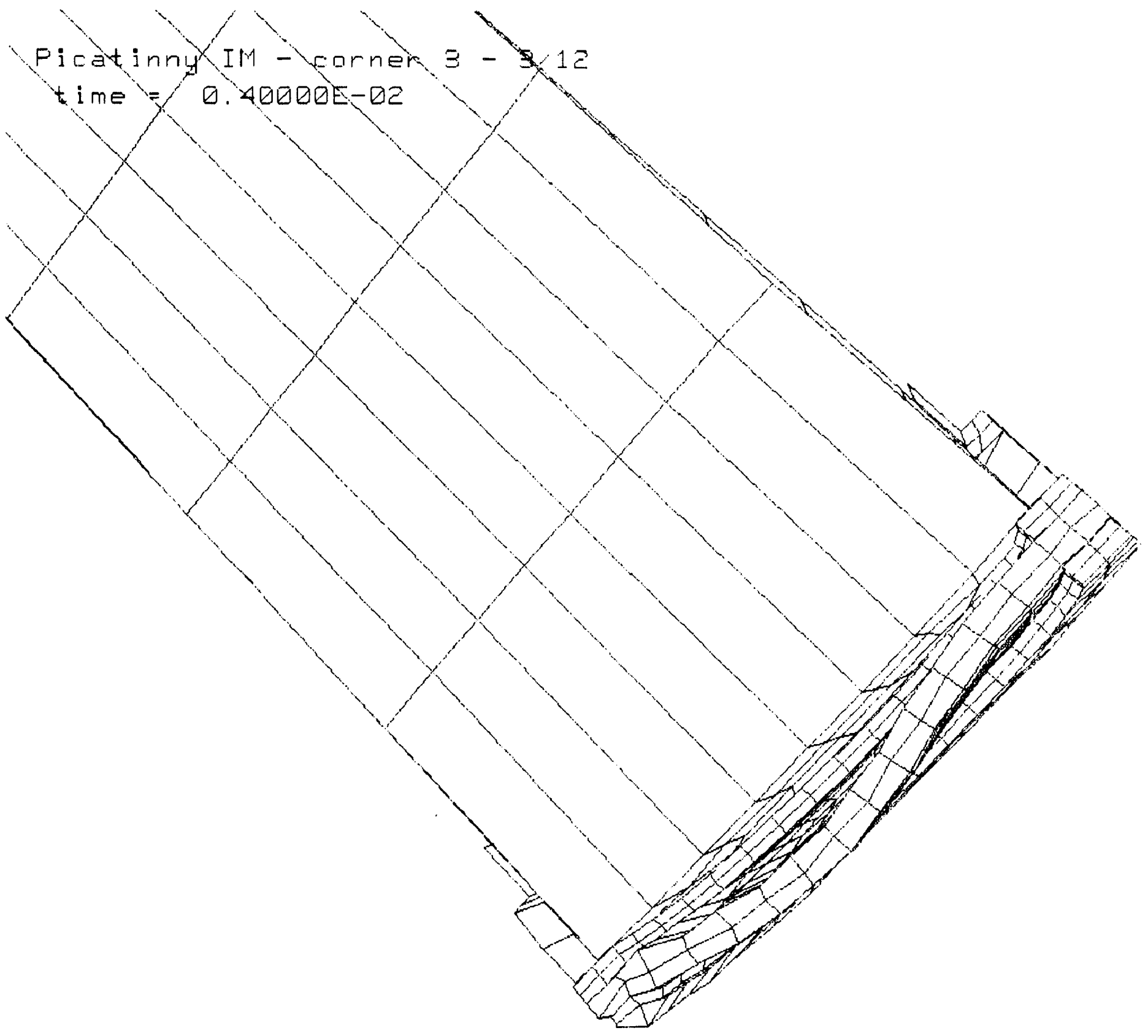

Fig. 33. Enlargement of the impacting corner during the initial impact. 
Picatinny IM - corner $3-3,12$
time $=0.1080 E E+E 0$

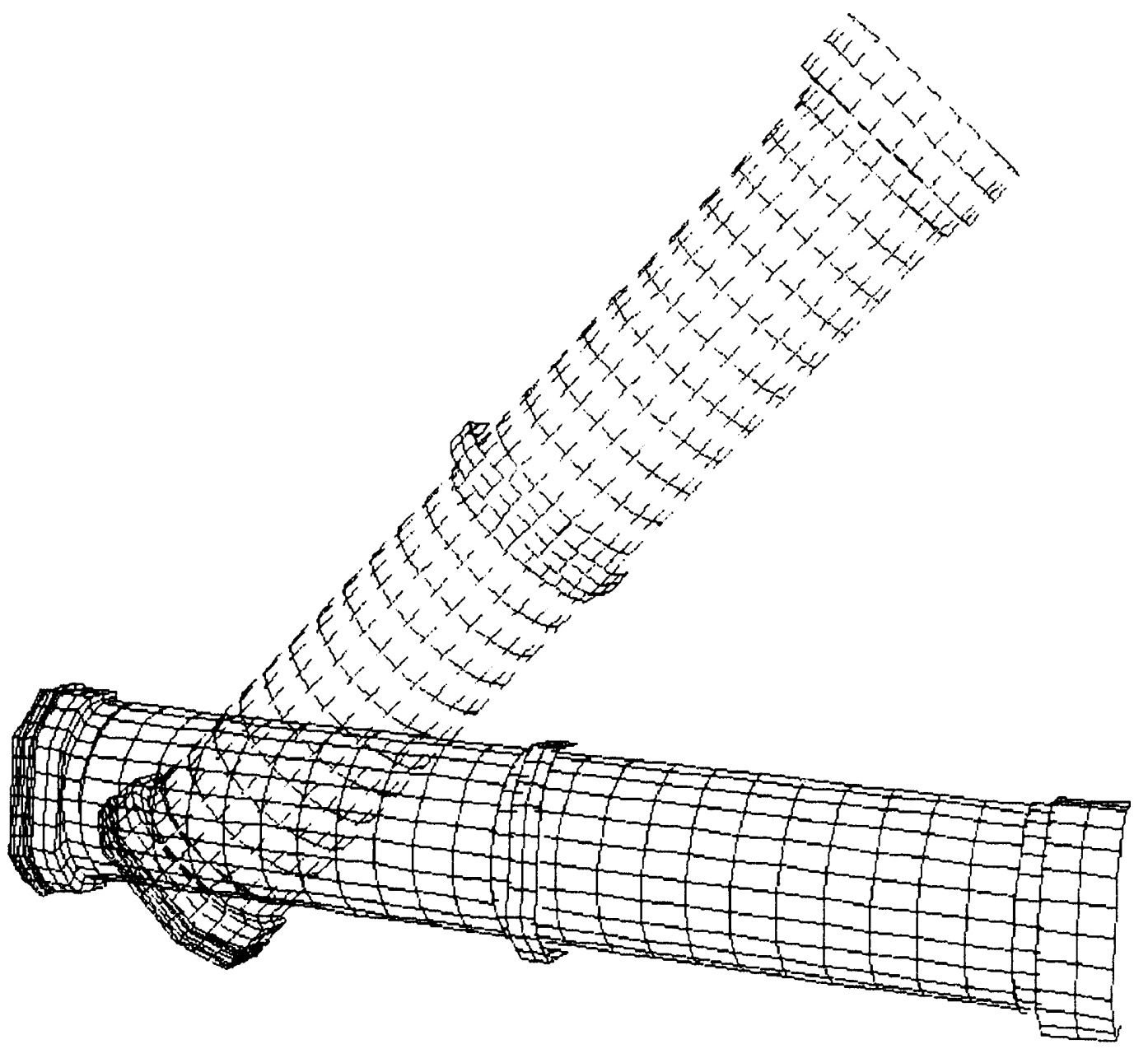

Fig. 34. Orientation of the container at $1.08 \times 10^{-1} s$ (dashed outline represents the original position). 
Picatinny IM - carner $3-312$

time $=0.12200 E+00$

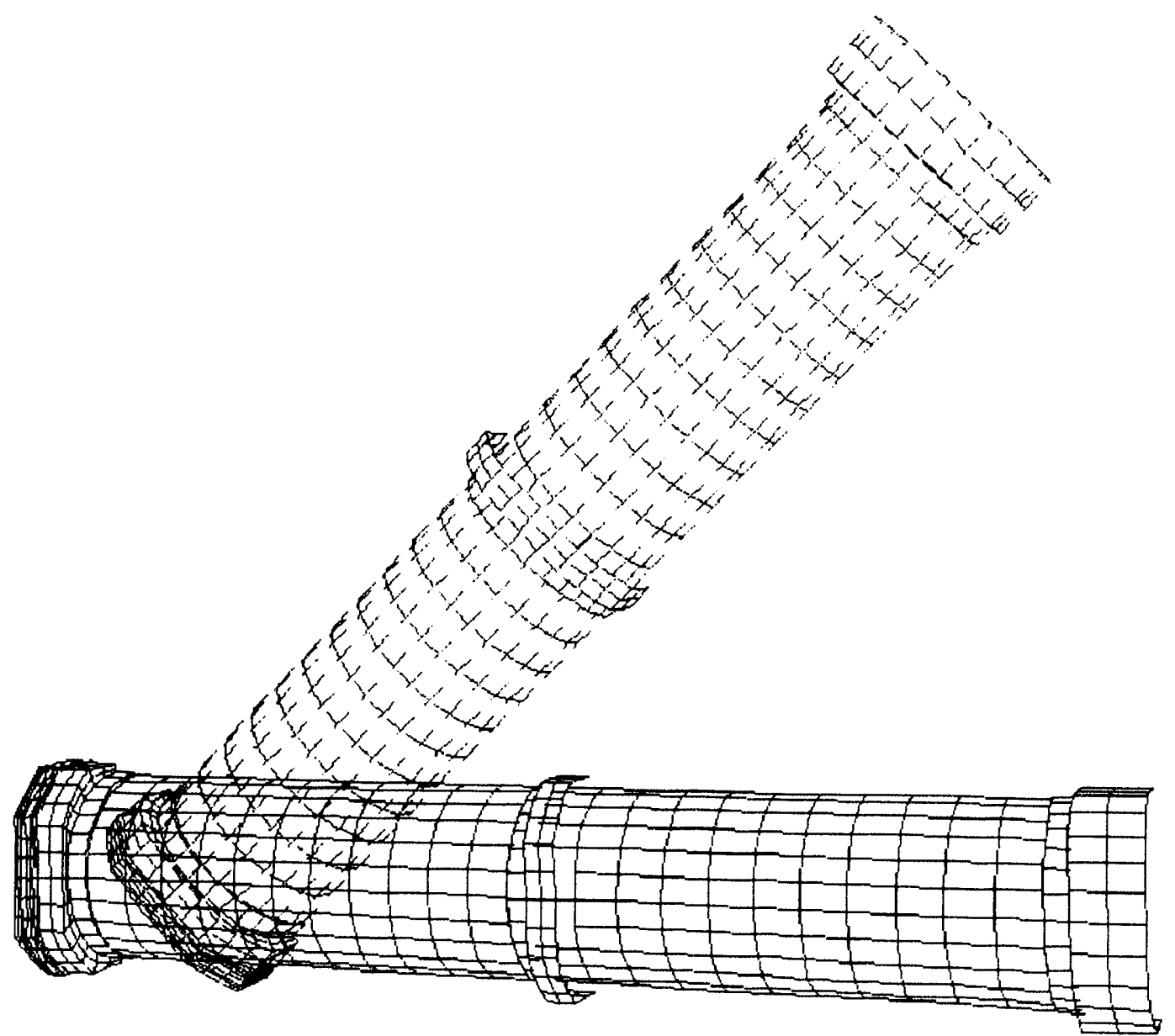

Fig. 35. Orientation of the container at $1.22 \times 10^{-1} \mathrm{~s}$ (dashed outline represents the original position). 


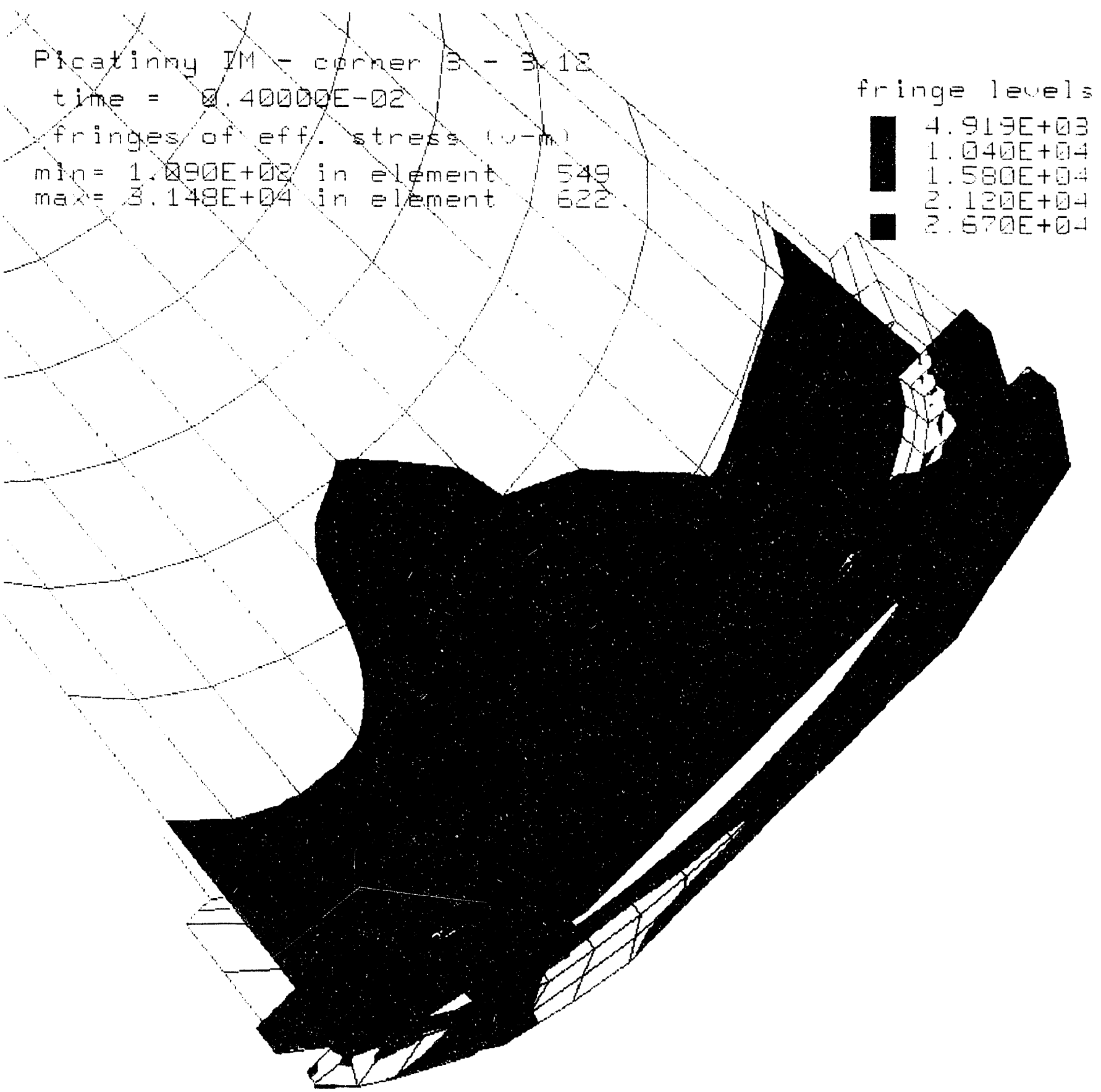

Fig. 36. Contours of effective stress in the impacting end of the container due to initial impact. 

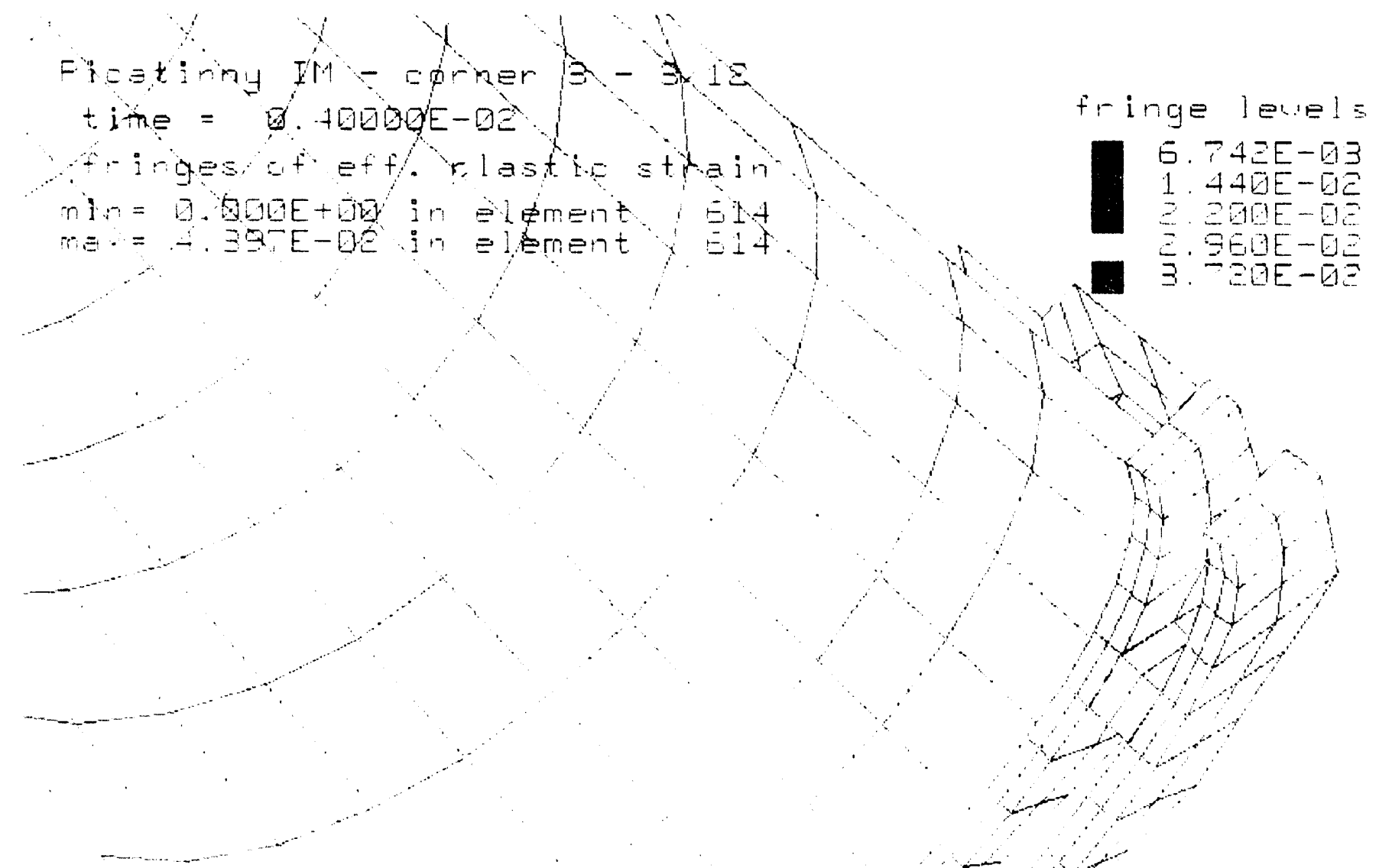

Fig. 37. Contours of effective plastic strain in the impacting end of the container due to initial impact. 


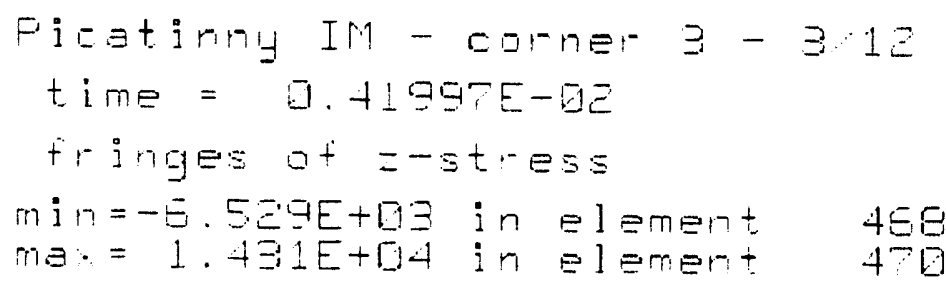

$$
\begin{aligned}
& \text { fripge letels } \\
& \text { - }-3.3+E+B \\
& \text { 引. } 3 \exists \boxminus E E+\square 3 \\
& \text { - }
\end{aligned}
$$
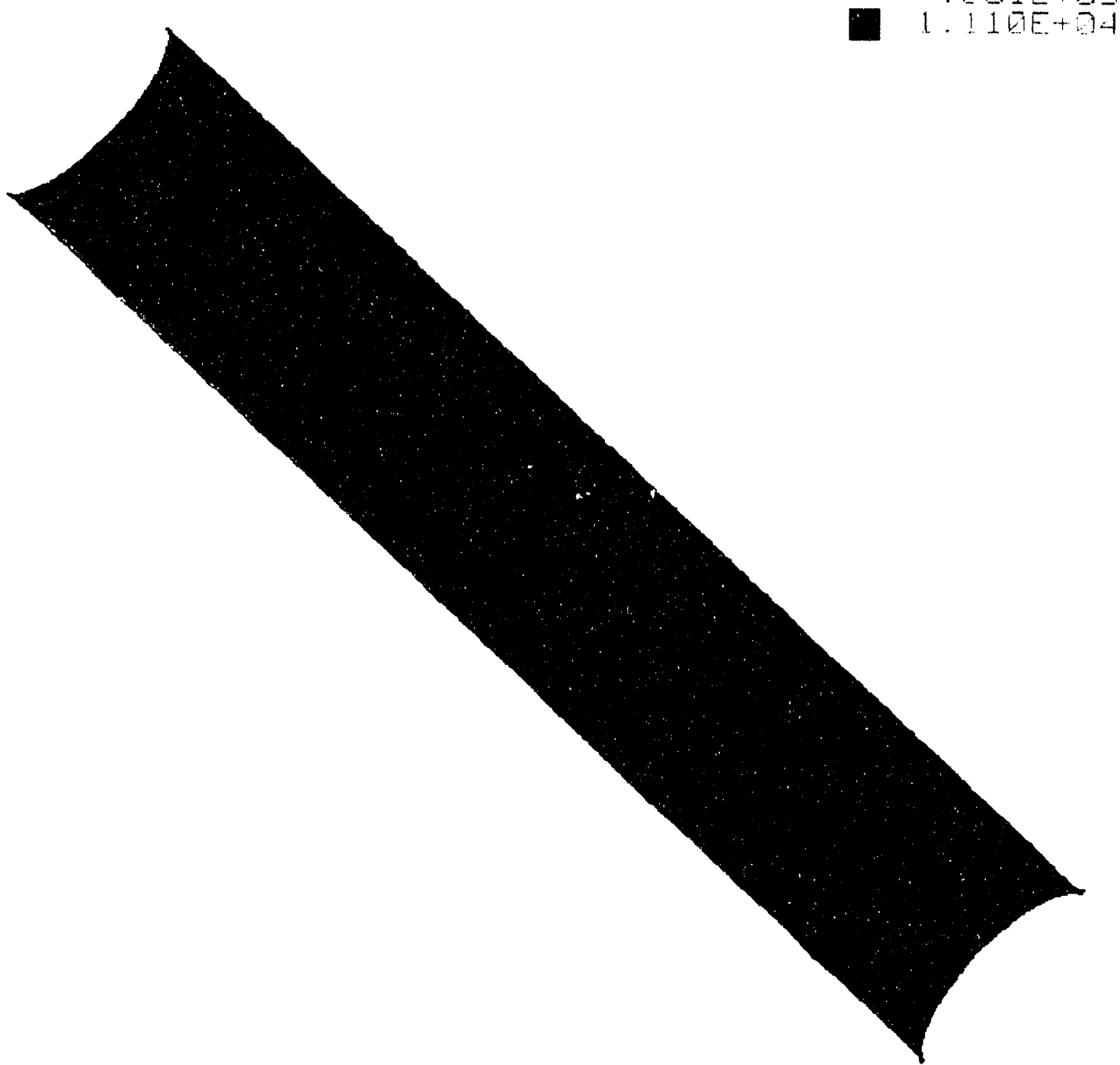

$-4$

$=$

Fig. 38. Contours of axial stress in the body due to the initial impact. 

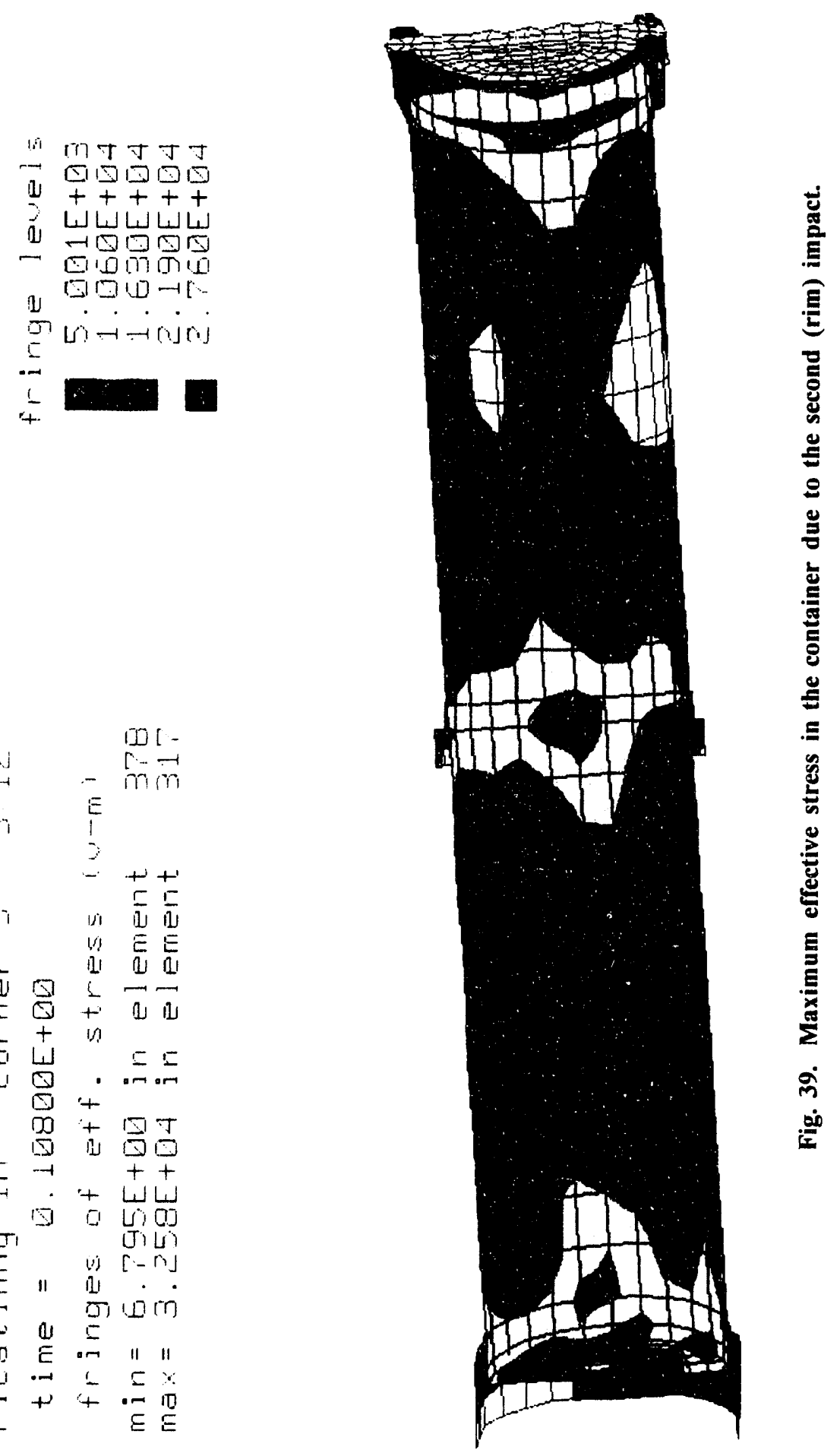

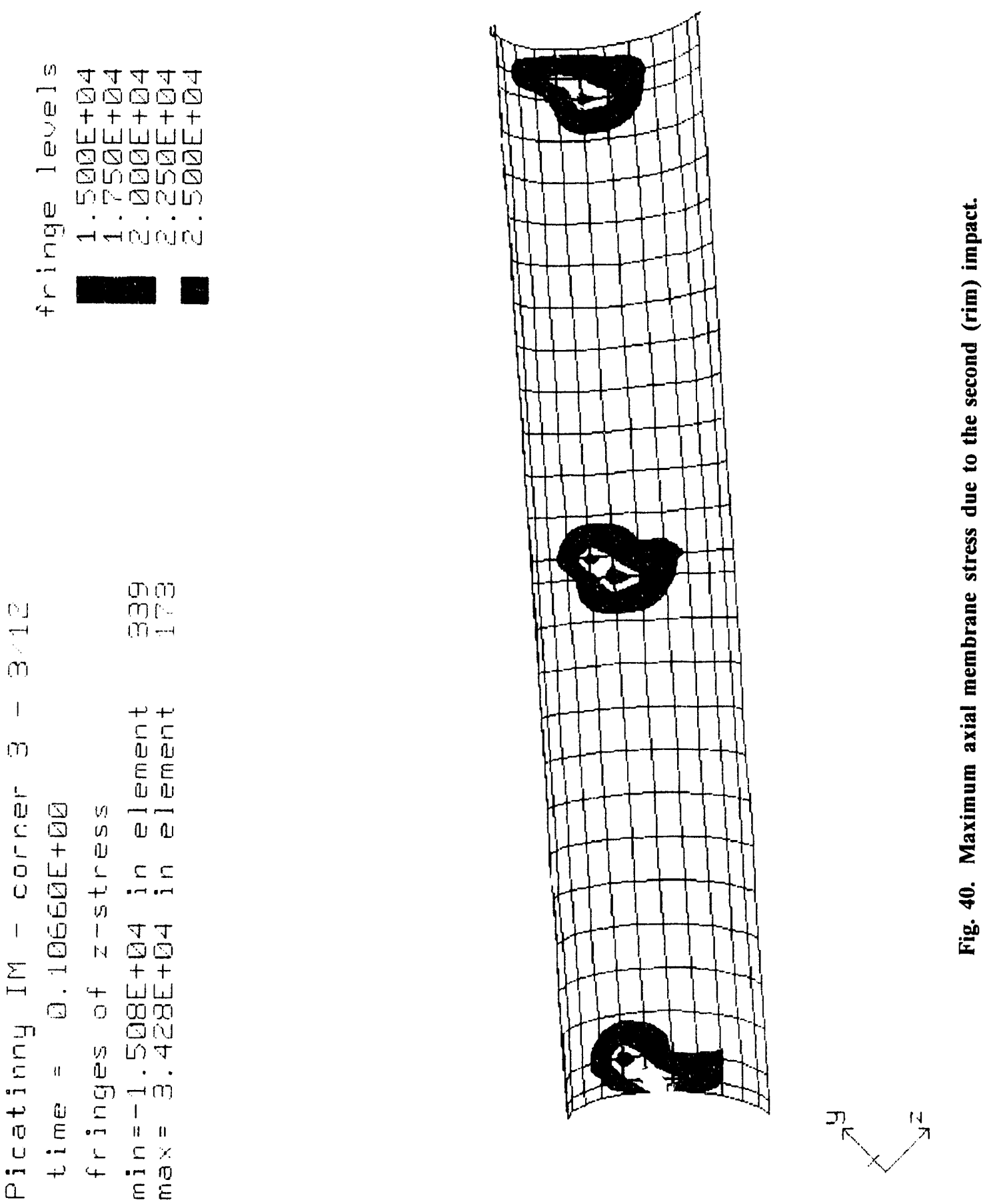


$$
\begin{aligned}
& \text { Picatinny IM - carner } \Xi-3.12 \\
& \text { time = Q.1ZZQDE+DQ } \\
& \text { fringes of eff. stress w-m! } \\
& \mathrm{min}=1.635 E+01 \text { in element } 421 \\
& \text { ma: }=3.259 E+04 \text { in } 3 \text { lement } 173
\end{aligned}
$$

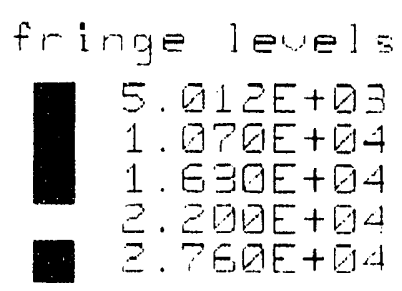

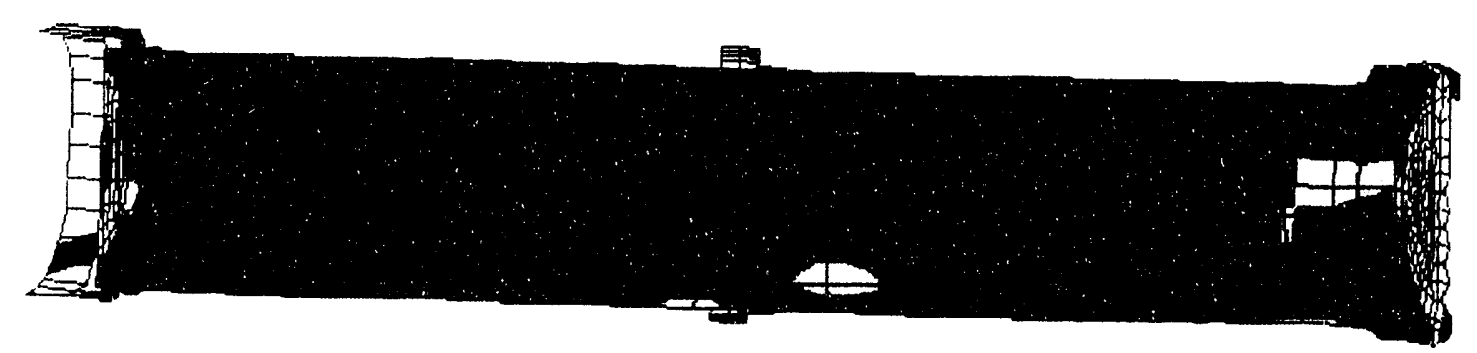

Fig. 41. Contours of maximum effective stress due to the third impact. 
Picatinny IM - corner $3-3-12$

time = $0.1224 \square E+\square \square$

fringle levels

fringes of z-stress

$\min =-2.765 E+04$ in element 173

$\max =2.048 E+04$ in element 304

1. QDQDE+D4

1. $250 E+04$

1. 5 Q $1 E+04$

1. P5VE+Q4

2. $. \square D E+Q A$

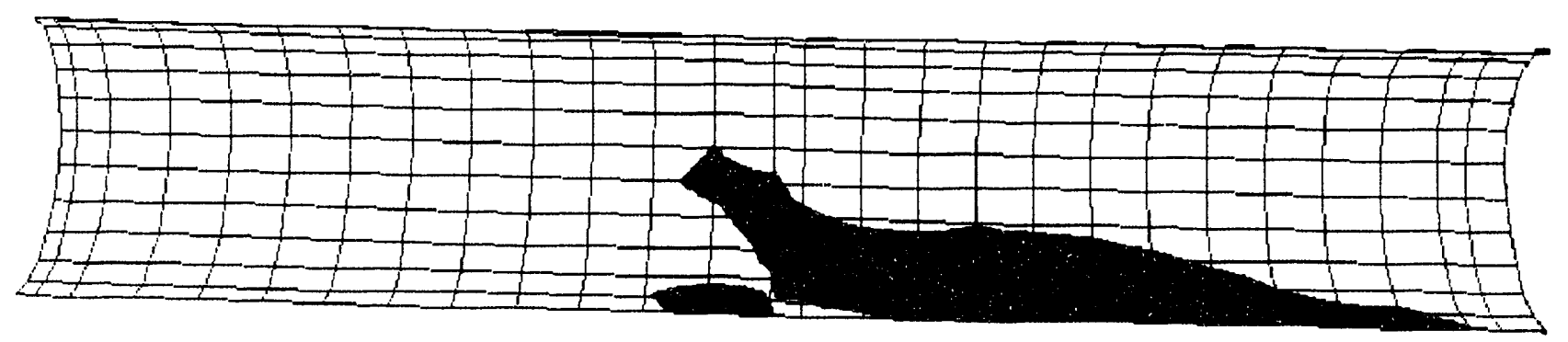

$y^{2}$

Fig. 42. Contours of maximum axial membrane stress due to the third impact. 
ORNL/ENG/TM-42

\section{INTERNAL DISTRIBUTION}

1. D. W. Webb

2. K. D. Handy

3-6. J. C. Walls

7. T. L. Ryan

8-10. J. H. Hannah

11-13. R. M. Davis
14. ORNL Patent Office

15. Central Research Library

16. Document Reference Section

17-18. Laboratory Records Department

19. Laboratory Records-Record Copy

\section{EXTERNAL DISTRIBUTION}

20. Robert J. Kuper, Chief, Packaging Division, SMCAR-AEP, Picatinny Arsenal, NJ 07806-5000

21. A. D'Angelo, Packaging Division, SMCAR-AEP, Picatinny Arsenal, NJ 07806-5000

22. W. Healy, Packaging Division, SMCAR-AEP, Picatinny Arsenal, NJ 07806-5000

23. G. L. Kent, PM-AMMOLOG, Picatinny Arsenal, NJ 07806-5000

24. N. F. Gravenstade, PM-AMMOLOG, Picatinny Arsenal, NJ 07806-5000

25. Assistant Manager, Energy Research and Development, U.S. Department of Energy, Oak Ridge Operations, P.O. Box 2001, Oak Ridge, TN 37831

26-27. U.S. Department of Energy, Office of Scientific and Technical Information, P.O. Box 62, Oak Ridge, TN 37831 

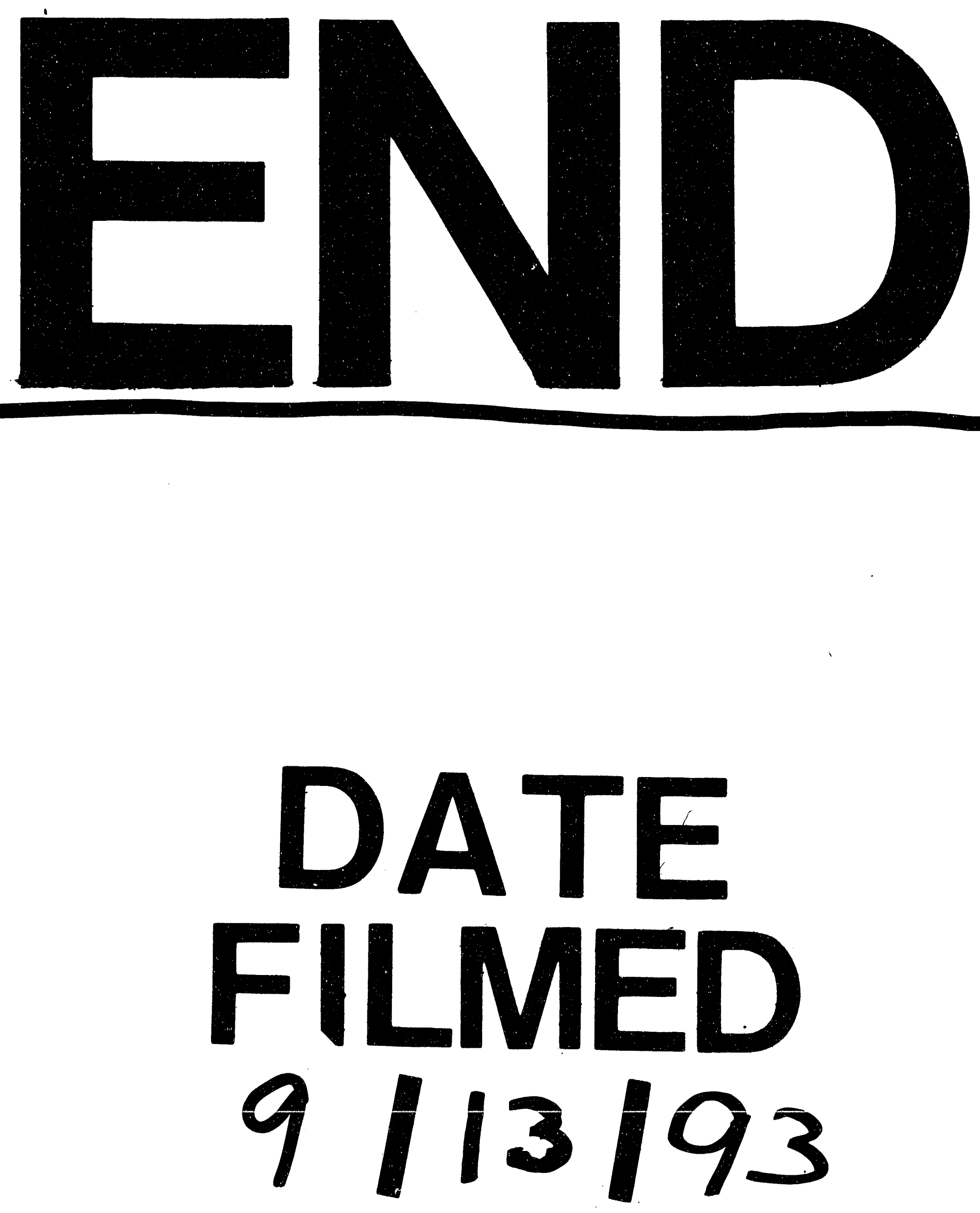
